\title{
Escaping the motherhood trap: Parental leave and childcare help young mothers to avoid NEET risks
}

Citation for published version (APA):

van Vugt, L., Nieuwenhuis, R., \& Levels, M. (2020). Escaping the motherhood trap: Parental leave and childcare help young mothers to avoid NEET risks. Maastricht University, Graduate School of Business and Economics. GSBE Research Memoranda No. 033 https://doi.org/10.26481/umagsb.2020033

Document status and date:

Published: 14/12/2020

DOI:

10.26481/umagsb.2020033

Document Version:

Publisher's PDF, also known as Version of record

\section{Please check the document version of this publication:}

- A submitted manuscript is the version of the article upon submission and before peer-review. There can be important differences between the submitted version and the official published version of record.

People interested in the research are advised to contact the author for the final version of the publication, or visit the DOI to the publisher's website.

- The final author version and the galley proof are versions of the publication after peer review.

- The final published version features the final layout of the paper including the volume, issue and page numbers.

Link to publication

\footnotetext{
General rights Owners
rights.

- You may freely distribute the URL identifying the publication in the public portal. please follow below link for the End User Agreement:

www.umlib.nl/taverne-license

Take down policy

If you believe that this document breaches copyright please contact us at:

repository@maastrichtuniversity.nl

providing details and we will investigate your claim.
}

Copyright and moral rights for the publications made accessible in the public portal are retained by the authors and/or other copyright owners and it is a condition of accessing publications that users recognise and abide by the legal requirements associated with these

- Users may download and print one copy of any publication from the public portal for the purpose of private study or research.

- You may not further distribute the material or use it for any profit-making activity or commercial gain

If the publication is distributed under the terms of Article $25 \mathrm{fa}$ of the Dutch Copyright Act, indicated by the "Taverne" license above, 
Lynn van Vugt, Rense Nieuwenhuis, Mark Levels

Escaping the motherhood trap: parental leave and childcare help young mothers to avoid NEET risks

RM/20/033

ISSN: $2666-8807$

\section{GSBE}

Maastricht University School of Business and Economics

Graduate School of Business and Economics

\section{P.O Box 616}

NL-6200 MD Maastricht

The Netherlands 


\title{
ESCAPING THE MOTHERHOOD TRAP: PARENTAL LEAVE AND CHILDCARE HELP YOUNG MOTHERS TO AVOID NEET RISKS*
}

\author{
Lynn van Vugt, Rense Nieuwenhuis \& Mark Levels
}

\begin{abstract}
WORDS
This paper explores to what extent and how the risk that young mothers become NEET (Not in Employment, Education or Training) later in life is related to family policy provisions (i.e. parental leave and Early Childhood Education and Care). We examine a three-staged process: the relation between (a) characteristics of family policies and the use of $i t,(b)$ the use of family policy provisions and NEET risks, and (c) the effectiveness of family policy provisions on the characteristics of these family policies. Combining data from the EU-LFS with macro-level indicators of family policies, we analyse NEET risks of 13,613 young mothers (20-29) in 27 EU-countries. We find that young mothers are more likely to take parental leave if it is paid for a longer period of time, and are more likely to use ECEC when childcare placement is guaranteed. Both parental leave and ECEC services are associated with lower NEET risks, as long as they are not used for overly short or long periods. However, this depends largely on the way parental leave is organised. In addition, in countries where ECEC is more affordable, young mothers who use ECEC are better protected against NEET risks later in life.
\end{abstract}

Keywords: NEET, motherhood, family policies, parental leave, early childhood education and care, European Union

* We would like to thank Dirk Hofäcker and the other participants of the ESPAnet 2020 Online Conference for their valuable feedback. We also would like to thank Per Bles and Stan Vermeulen for their valuable comments and suggestions. This study has received funding from NWO/DFG/ANR/ESRC on NEET with ORA grant agreement No. 464-15-186 and from the European Union's Horizon 2020 research and innovation programme InGRID-2 under grant agreement No. 730998. 
Lynn van Vugt

Maastricht University

ROA

P.O. Box 616

NL-6200 MD Maastricht

The Netherlands

l.vanvugt@maastrichtuniversity.nl

Mark Levels

Maastricht University

ROA

P.O. Box 616

NL-6200 MD Maastricht

The Netherlands

m.levels@maastrichtuniversity.nl
Rense Nieuwenhuis

Swedish Institute for Social Research (SOFI)

Stockholm University

S-106 91 Stockholm

Sweden

rense.nieuwenhuis@sofi.su.se 


\section{INTRODUCTION}

Motherhood is associated with socio-economic penalties for young women in many countries. Young mothers are more likely to drop out of school (OECD, 2005) and are more likely to become unemployed or inactive compared to childless women (Nieuwenhuis, Need, \& Van der Kolk, 2012; Van der Lippe \& Van Dijk, 2002). In this paper, we study the extent to which young mothers are more likely to disengage from education and the labour market and how the differences across countries can be explained.

While the increases in female labour force participation and women's higher education are widespread trends, young women are much more likely to become Not in Employment, Education or Training [NEET] than young men (Carcillo, Fernández, Königs, \& Minea, 2015; Eurofound, 2012, 2016; OECD, 2019b). Being NEET not only affects women's later labour market outcomes, but it is also associated with early marriage or cohabiting, feelings of dissatisfaction with life, lack of a sense of control and experiencing problems in life (Bynner \& Parsons, 2002).

Figure $1^{l}$ shows that large cross-national variation exists in the percentage of young mothers who are NEET. The average percentage of NEETs among young mothers in the European Union (EU) is $37.1 \%$ and ranges from $5.5 \%$ in Norway to $67.5 \%$ in Italy.

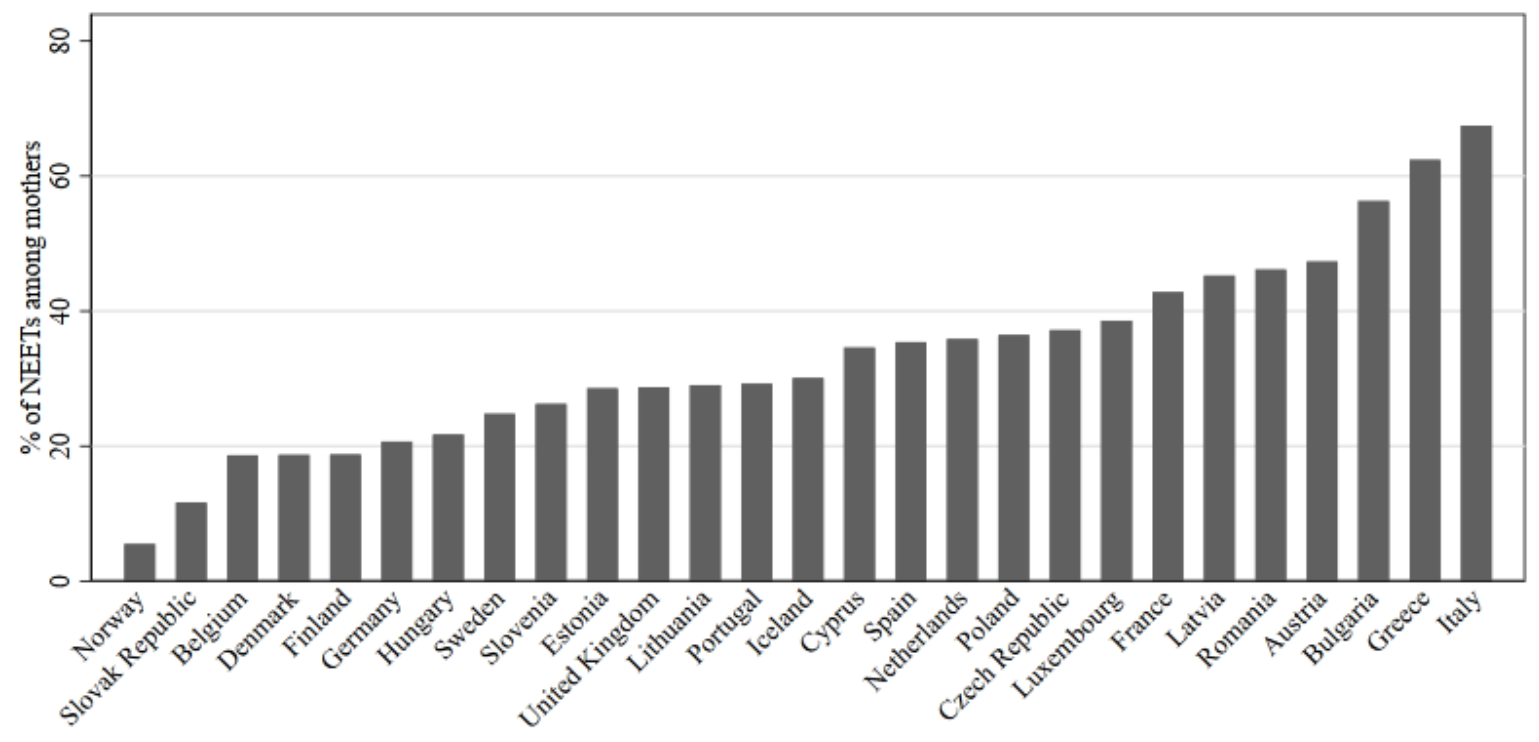

Figure 1. Percentage of NEETs among young mothers in the EU (2010) 
Two explanations are commonly suggested for this cross-national variation. First, compositional differences such as educational and socio-economic background among young mothers might be crucial in explaining the cross-national variation of NEET risks (Eurofound, 2012, 2016). Second, contextual differences pertaining to laws, institutions and policies may play a role. To the best of our knowledge, no empirical evidence is available about institutional and policy contexts that shape the relation between young motherhood and NEET. However, the vast literature on women's employment brings family policy into focus. Therefore, we propose that family policies have the potential to help explain crossnational differences in the likelihood of young mothers becoming NEET. Research about female employment has shown that institutional arrangements such as family policies support women in their (re-)entrance in the labour market (Nieuwenhuis et al., 2012; Pettit \& Hook, 2005). Although this research only focusses on the labour market, we argue based on Becker's 'new home economics' (1965, 1981) that this also holds for women's (re-)engagement in education, because time spend on parental obligations limits the time spent on education. When young mothers are able to reallocate part of their parenting duties, they can reconsider their balance between education and family life.

In this paper, we focus on young mothers and not on young women in general. First, the patterns of vulnerability in NEETs differ across subgroups, therefore "disentangling the subgroups [...] is essential for a better understanding of their different characteristics and needs, and for tailoring effective policies to reintegrate them into the labour market or education" (Eurofound, 2017, p.55). In this case, young mothers have other needs than young women without children. For example, young mothers may be unable to work or study because of childcare responsibilities, whereas women without children have other reasons for being unable to work. The specific needs and characteristics of these mothers should be taken into account in order to effectively reintegrate young mothers who have become NEET. Second, mothers are the primary target group of family policies. The efficiency and effectiveness of these policies are therefore particularly crucial for mothers and less important for young women without children.

Family policies affect the likelihood of young mothers becoming NEET in various ways. Most directly, they can shorten the distance to the labour market by offering parental leave benefits or childcare services. However, they can also affect earlier decision-making. For example, young mothers 
can decide to drop out of school or stop working before or immediately after childbirth. To shed light on why some young mothers are more likely to become NEET and explain why contexts matter, we dissect the decision-making process that leads to young mothers becoming NEET in three stages. First, we look at the extent to which the use of parental leave and early childhood education and care (ECEC) is associated with the related family policies within a country. Second, we discuss how the use of these family policies could help young mothers reconsider their decision about the (re-)engagement in employment or education and therefore make them more or less likely to become NEET. Third, we assess whether the relation between the use of parental leave/ECEC and NEET is moderated by family policies. In order to understand the complex ways in which these policies affect outcomes, we study how they affect different stages in the process leading to a NEET status.

We focus on two types of family policies that are commonly considered key to supporting social rights for women's employment in general and that vary considerably across countries: parental leave benefits and public ECEC services (Gornick \& Meyers, 2003; Olivetti \& Petrongolo, 2017). Parental leave benefits enable young mothers to temporarily disengage from the labour market to take care of their children, while public ECEC services may facilitate them to combine motherhood with employment, training or enrolment in education.

This leads to the following research questions: a) What aspects of family policies can explain differences between countries in the degree to which young mothers use parental leave and ECEC services? b) To what extent is the use of parental leave or ECEC (among young mothers) associated with becoming NEET later in life? c) To what extent can aspects of family policies explain differences between countries in how parental leave and ECEC help protect young mothers from becoming NEET?

We answer our research questions using data from the European Union Labour Force Survey (EULFS). This is a large household survey on labour market participation conducted in all European Union member states, as well as Iceland, Norway and Switzerland. We use wave 2010, including the ad hoc module 'Reconciliation between work and family life'. An advantage of this dataset is that the ad hoc module pays special attention to work-related questions after childbirth such as use of childcare and maternity leave. Furthermore, we use macro-data from MultiLinks, OECD and the OECD family database to collect data about the different family policies across European countries. We study young 
mothers aged 20-29 with at least one own/spouse's child up to the age of 8 living in the household. Our final sample consists of 13,613 young mothers in 27 European Union countries. We use random slope multilevel designs to test the macro-micro hypotheses against cross-national data.

This research complements and extends previous research in the following ways. First, it examines NEET as a gendered phenomenon, by introducing a focus on motherhood and family policies as important determinants. Therefore, it is important to look at how family policies affect the process of becoming NEET, with a primary focus on mothers, because they (and their children) are the target group of parental leave and ECEC policies.

A second contribution is that the data enables us to study a sufficient number of countries where we compare different national family policies. The data also enables us to look at certain control variables to account for different demographic compositions across countries. This is important to prevent biased estimates of the impact of family policies.

In addition to the scientific contributions, examining NEET as a gendered phenomenon with a focus on the potential role of motherhood has important policy implications. Young people not in employment, education or training are a major policy concern and, if motherhood indeed is a strong predictor of NEET, then policy makers could target the different needs and characteristics of this subgroup of NEETs (mothers) when considering policy measures. Current NEET policies are mainly concerned with helping people return to work or school. For instance, a new set of policies was proposed by the European Commission on 27 April 2010 to (re-)engage young people with the labour market or education (European Commission, 2010). However, support for labour market (re-)engagement without affordable childcare may not help NEETs who have a child. Therefore, it could be more important to look at family-related policies rather than general labour market policies when examining the relationship between young motherhood and the risk of becoming NEET later in life.

\section{THEORY \& HYPOTHESES}

In this section, we develop hypotheses on how two main types of family policies are related to NEET risks: parental leave and early childhood education and care (ECEC). Our main argument is that time 
devoted to parental obligations cannot be spent on work or education. Paid parental leave enables young mothers to temporarily disengage from the labour market (with job protection and partial income replacement) to care for their children, while ECEC services may facilitate them to combine motherhood with employment, training or enrolment in education.

The availability of these family policies differs widely between countries (Thévenon, 2011; Thévenon \& Luci, 2012). To understand how this variation is related to NEET risks among young mothers, we examine three stages in the process: a). the extent to which family policies are associated with their use, b). whether these policies help young mother reduce NEET risks later in life, and c). whether the effectiveness of parental leave and ECEC is moderated by the related family policies. These stages are illustrated in Figure 2.

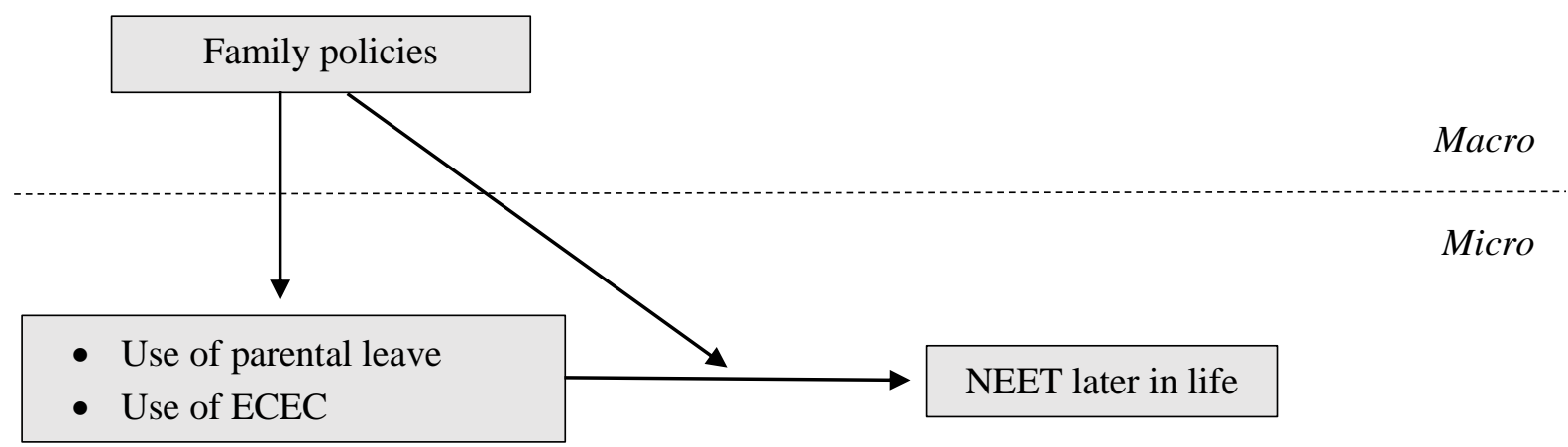

Figure 2: Visual overview of stages that describe how family policies affect NEET risks (among young mothers)

According to the 'new home economics' (Becker, 1965, 1981), individuals allocate time and financial resources to reach their goals. In this case, young mothers have to decide whether the benefits of work or education outweigh the benefits of staying at home. The time spent in work or education cannot be spent on parental obligations. The decision-making process of young mothers depends on multiple facets such as economic circumstances and marital status. It is also based on the duration of paid parental leave and the availability and affordability of ECEC services. A lack of these aspects of family policies may be a crucial determinant of young mothers' decision-making process. Now we disentangle the three aforementioned stages and formulate hypotheses. 


\section{PARENTAL LEAVE}

For the first stage, we look at the mechanisms through which the length of paid parental leave relates to the NEET risks of young mothers. Parental leave supports parents in temporary caregiving while allowing them to return to the same job after childbirth and often providing some level of income replacement until then. Across Europe, large variation exists in terms of the length of leave and the compensation level (Thévenon, 2011; Thévenon \& Luci, 2012; van Belle, 2016). Depending on the length of paid parental leave, young mothers consider their decision about the reallocation of time between parental obligations and work. ${ }^{2}$ We expect that if a state subsidises long-term parental leave benefits, young mothers are more likely to take parental leave. Longer paid parental leave makes the use of parental leave less of a financial burden for more families across the income distribution, because they do not miss out on income they would otherwise generate. Furthermore, previous research has also shown that the level of contribution from the state towards work a family arrangements, affects the employers' decision to adopt work and family arrangements (Den Dulk, Peters, \& Poutsma, 2012). Therefore, in countries with longer paid parental leave durations, employers are also more used to the fact that mothers take parental leave. However, when the state only guarantees a short period of paid parental leave, we expect that mothers would be more likely to quit their job and take care of their children, which makes them not eligible anymore for taking parental leave. Therefore, we hypothesise that:

Hypothesis la: Young mothers are more likely to use parental leave in countries that provide longer periods of paid parental leave compared to countries with shorter periods of paid leave.

The second stage focuses on the relation between young mothers using parental leave and their subsequent probability of becoming NEET. We assume that the time devoted to taking care of children limits the time spent in work or education. However, for parental leave this can be combined: if young mothers are taking parental leave, their job protection maintains their attachment to the labour market while they take care of the child. Therefore, young mothers who use parental leave are more likely to return to work at the end of their parental leave and this lowers their risk of becoming NEET. 
However, we do not expect parental leave to unequivocally reduce the risk of becoming NEET, as overly long durations of parental leave have been identified as potentially problematic. Previous research has shown a curvilinear relationship between the length of paid leave and young mothers' labour market attachment (Akgunduz \& Plantenga, 2012; Del Boca, Pasqua, \& Pronzato, 2008; Nieuwenhuis, Need, \& Van der Kolk, 2017; Thévenon \& Solaz, 2014). An overly long parental leave creates more distance from the labour market due to human capital depreciation and experience loss, which creates an obstacle for women to return to work (Boeckmann, Misra, \& Budig, 2014; Nieuwenhuis et al., 2017; Pettit \& Hook, 2005). Shorter periods of paid leave maintain the labour force attachment and decreases the motherhood penalty of human capital and experience loss compared to longer leave. However, young mothers who have no leave or only very short leave are more likely to quit the work force (Nieuwenhuis et al., 2012; OECD, 2011). Therefore, we also formulate a curvilinear hypothesis that takes into account the different lengths of parental leave and the subsequent probability of becoming NEET. We expect that overly short or overly long lengths of parental leave increase the likelihood of becoming NEET compared to moderate lengths of leave.

Hypothesis 1b: Young mothers who use parental leave are less likely to become NEET later in life than young mothers who do not use parental leave, but young mothers who use overly short or overly long periods of parental leave are more likely to become NEET later in life than young mothers who use a moderate period of parental leave.

In the third stage, we look at the effectiveness of family policies. We distinguish between how long individual mothers use leave and the maximum period of parental leave the country offers. We expect that the differences in NEET risks between young mothers who use parental leave and those who do not will be larger in countries that provide longer periods of paid parental leave. In these countries, the use of parental leave is more accepted by both the state and employers. However, if young mothers are not using parental leave in these countries, other factors might be more important for the decisionmaking process. For instance, these young mothers may not have had a job before childbirth and therefore were not entitled to paid parental leave, or they may have preferred being a homemaker or focusing on the care of their child(ren). In countries with family policies that support fewer months of 
paid parental leave, we expect a smaller difference between young mothers who do and do not use parental leave, because the distance to the labour market for young mothers who use parental leave will not increase dramatically compared to young mothers who use no parental leave.

However, if countries support overly long periods of paid parental leave, this might shape the opportunity structure differently. For young mothers living in countries that support less paid parental leave, we expect a stronger relationship between the long use of parental leave and NEET risks, because taking more leave could send a negative signal to employers. The use of long periods of parental leave also comes with the loss of job-specific human capital and experience that may be more detrimental compared to the use of shorter parental leave. On the other hand, in countries that support taking longer periods of paid parental leave, long parental leave is more common and also more accepted by employers, and therefore less seen as a disadvantage (Den Dulk et al., 2012).

Hypothesis 1c: In countries with longer availability of paid parental leave, young mothers who use parental leave are better protected against NEET risks later in life than in countries with shorter periods of paid parental leave.

Hypothesis 1d: In countries with longer availability of paid parental leave, young mothers who take overly long periods of parental leave are better protected against NEET risks later in life than in countries with shorter periods of paid parental leave.

\section{ECEC}

The first stage of analysing the effectiveness of ECEC services pertains to their use by young mothers, which depends on a number of factors, including availability and affordability (Eurofound, 2013; Gambaro, Stewart, \& Waldfogel, 2015; Yerkes \& Javornik, 2018). Depending on how the ECEC policy is implemented in a country, young mothers reallocate time between parental obligations and work/education obligations. We expect that if if governments policies guarantee an available spot in formal ECEC services for children, young mothers are more likely to make use of ECEC services than in countries where ECEC is not guaranteed by the state and young mothers have to search for an 
available spot themselves. In addition, lower costs for ECEC services will make the use of ECEC services more affordable for more families across the income distribution. Therefore, we hypothesise that the lower the costs of ECEC services, the more likely young mothers are to make use of ECEC services.

Hypothesis 2a: Young mothers are more likely to use ECEC services in countries where ECEC is guaranteed compared to countries where ECEC is not guaranteed.

Hypothesis $2 b$ Young mothers are more likely to use ECEC services in countries where ECEC is more affordable compared to countries where ECEC is less affordable.

The second stage concerns the relation between young mothers' use of ECEC and subsequent NEET risks. We expect that young mothers want to maximise utility and make a trade-off between the use of ECEC services and the time not spent in employment or education. The time devoted to taking care of children limits the time spent in the labour force or education. When young mothers use ECEC services, they can reconsider their balance between work/education and family life. A benefit of using ECEC services is that young mothers are able to spend more time in work or education. Therefore, we hypothesise that young mothers who use ECEC services are more likely to continue (part-time) working (OECD, 2011) or studying and thus less likely to become NEET.

Hypothesis 2c: Young mothers who use ECEC services are less likely to become NEET later in life compared to young mothers who do not use ECEC services.

The third stage addresses whether the effectiveness of using ECEC depends on its context. Family policies regarding ECEC shape the opportunity structure of young mothers in at least two different ways. First, when countries better organise the opportunities to use ECEC services, young mothers across different backgrounds - in particular those at higher risks of becoming NEET - may be more likely to use ECEC services compared to young mothers living in countries with low state support. In other words, higher levels of government support, such as guaranteed places and lower fees, will result 
in more universal use; this also means that ECEC is more likely to be used by those who might need it most to avoid becoming NEET. Secondly, as employers respond to the policy context, and when the use of ECEC is highly accepted in a country, employers' perceptions of the employability of young mothers are more likely to lead to them treating young mothers in the labour market differently than in countries that provide less support for ECEC services. We expect that in countries with large support for ECEC services, employers are more likely to offer flexible working hours to reconcile the use of ECEC services with work. Moreover, we expect less discrimination from employers against young mothers in these countries, since having a child is less of a burden than in countries where the state does not support the use of ECEC services. The same holds for education systems in which young mothers can study part-time to combine education and parental obligations. Therefore, we hypothesise that the effectiveness of using ECEC in relation with the likelihood to become NEET is stronger in countries that provide better access to ECEC services.

Hypothesis 2d: In countries where ECEC is guaranteed, young mothers who use ECEC are better protected against NEET risks later in life than in countries where ECEC is not guaranteed.

Hypothesis 2e: In countries where ECEC is more affordable, young mothers who use ECEC are better protected against NEET risks later in life than in countries where ECEC is less affordable.

\section{DATA, MEASUREMENTS AND METHODS}

\section{DATA}

The European Union Labour Force Survey (EU-LFS) is a large cross-country household survey on labour market participation conducted in 28 European member states, as well as Iceland, Norway and Switzerland. To test our hypotheses, we analysed data from 2010, including the 2010 ad hoc module 'Reconciliation between work and family life'. This ad hoc module combines information from the original EU-LFS with specific topical data on work-related questions after childbirth. Furthermore, we 
used macro-data from MultiLinks, OECD and the OECD family database to test for the different aspects of family policies.

We selected young mothers aged 20-29 with at least one child up to the age of 8 living in the household. ${ }^{3}$ We did not analyse data from Ireland because of missing data on the micro variable measuring the use of parental leave, and we removed Malta and Croatia because of the low number of young mothers in the dataset. These selections resulted in a total sample of $N=13,693$ young mothers with a child below age 9 . We deleted cases with missing values on the NEET variable $(N=4)$ and cases with missing values on at least one of the micro-indicators $(N=108)$. These selections resulted in a total working sample of $N=13,613$ young mothers aged 20-29 from 27 countries with a child living in the household up to age 8 . However, the number of countries differs in some analyses because of missing data for some of the macro indicators (see Appendix, Table A2).

\section{MEASUREMENTS}

Descriptive statistics of all variables are presented in Table 1 (individual-level variables) and Table 2 (country-level variables). We describe how the variables are measured below.

\section{Individual-level variables}

- NEET: Measures whether the main status of young mothers was NEET during the reference week. Young mothers who carried out a job or profession, including unpaid work for a family business or holding and including an apprenticeship or paid traineeship were not labelled as NEETs. The same holds for young mothers with a main status as: pupil, student, further training, or unpaid work experience. We also did not label mothers as NEET if they were on maternity or parental leave, since these mothers still have an employment contract and job security. We labelled young mothers as NEET when they were unemployed, in retirement or early retirement or had given up a business, were permanently disabled, fulfilled domestic tasks or had other inactive reasons.

Since the question about the main activity status was not asked in the survey in Germany, Norway or the United Kingdom, we constructed the NEET status based on ILO work status and education status. In these countries, young mothers who were active as a student or apprentice 
during the last 4 weeks or employed during the last week before the survey were not labelled as NEET. We labelled young mothers who were not in education or an apprenticeship in the last 4 weeks before the survey and not in employment during the reference week as NEET. Overall, $37.1 \%$ of the young mothers in our sample are categorised as NEET.

- Use of parental leave: Whether young mothers used full-time parental leave for at least one month for their youngest child. This question was only asked to young mothers with at least one own/spouse's child up to the age of 8 living in the household. In general, $37.2 \%$ of the young mothers in our sample had taken more than 1 month of parental leave. Young mothers who had not used at least one month of full-time parental leave are the reference category.

- Length of parental leave use: To examine how long individual young mothers used their parental leave rights, we created three categories: up to 3 months (76.6\%), 3-12 months (9.9\%) and more than 1 year (13.5\%). Young mothers who were still on parental leave were deleted from the related analyses since their parental leave length is unknown. Young mothers who had used three to twelve months of parental leave are the reference category.

- Use of ECEC: Whether young mothers used formal childcare services (including paid childminders, pre-school; apart from compulsory school) for their youngest child and, if so, how many hours a week. This question was only asked to young mothers with at least one child up to age 14 living in the household. However, since the variable based on the use of parental leave is asked to young mothers with at least one child up to the age of 8 living in the household, we took the same sample of young mothers for use of ECEC. 32.6\% of mothers used ECEC services. Young mothers who had not used any ECEC are the reference category.

- Education level: Highest level of education or training successfully completed (ISCED-97) in three categories: low (no formal education, ISCED 1 and 2), medium (ISCED 3 and 4) and high (ISCED 5 and 6). In the sample, $28.3 \%$ were low educated, $52.4 \%$ medium educated and $19.3 \%$ highly educated. Young mothers with low educational attainment are the reference category.

- Age: We measured age in two categories, 20-24 years (23.8\%) and 25-29 years $(76.2 \%)$. The youngest group is the reference category. 
- Migration background: Based on country of birth, measured in three categories: native (national/native of own country), foreigner from country in Europe (EU15, NMS10, NMS3, NMS13, EU28, EFTA, other Europe, Europe outside EU28) and foreigner from outside Europe (North Africa, other Africa, Near and Middle East, East Asia, South and South East Asia, East and South Asia, North America, Central America and Caribbean, South America, Australia and Oceania, Latin America and North America). For Germany, migration background is distinguished by nationality because the country of immigrant origin can only be determent via the question about nationality. In our sample, $85.9 \%$ is native and this category forms the reference category. Also, 8.5\% was born in another European country and 5.6\% was born outside Europe.

Table 1. Descriptive statistics on individual-level variables

\begin{tabular}{lrrrrr}
\hline & $\mathbf{N}$ & \multicolumn{1}{c}{ \% } & SD & Min. & Max. \\
\hline NEET & 13,613 & 37.1 & 0.5 & 0 & 1 \\
Use of parental leave & 13,613 & 37.2 & 0.5 & 0 & 1 \\
Length of parental leave use & & & & & \\
$\quad$ Up to 3 months & 11,694 & 76.6 & 0.3 & 0 & 1 \\
$\quad$ 3-12 months & 11,694 & 9.9 & 0.4 & 0 & 1 \\
$\quad$ More than 1 year & 11,694 & 13.5 & 0.3 & 0 & 1 \\
Use of ECEC & 13,613 & 32.6 & 0.5 & 0 & 1 \\
Education level & & & & & \\
$\quad$ Low & 13,613 & 28.3 & 0.5 & 0 & 1 \\
$\quad$ Medium & 13,613 & 52.4 & 0.5 & 0 & 1 \\
$\quad$ High & 13,613 & 19.3 & 0.4 & 0 & 1 \\
Age $\quad 13,613$ & & & & \\
$\quad$ Age 19-24 & 13,613 & 23.8 & 0.4 & 0 & 1 \\
$\quad$ Age 25-29 & 13,613 & 76.2 & 0.4 & 0 & 1 \\
Migration background & & & & & \\
$\quad$ Native & 13,613 & 85.9 & 0.3 & 0 & 1 \\
$\quad$ Foreigner from Europe & 13,613 & 8.5 & 0.3 & 0 & 1 \\
$\quad$ Foreigner from outside Europe & 13,613 & 5.6 & 0.2 & 0 & 1 \\
\hline Note: the number of individuals is lower for the variable on the length of parental leave use, because we did not \\
include mothers who were still on parental leave since their length of parental leave use is unclear
\end{tabular}

\section{Country-level variables}

- Paid parental leave duration: Indicates full-time-equivalent paid parental leave (including maternity leave) measured in total leave time in months weighted by the level of wage-replacement in 2009 (Multilinks, 2011). This index ranges from 3 to 24 months with a mean of 10.1 months and a standard deviation of 6.5 months. A higher score means a longer period of paid parental leave. 
- Guaranteed childcare placement: Individual entitlement to childcare for children under the age of 3 in 2009 (Multilinks, 2011). This dummy distinguishes countries with guaranteed access to childcare from those without guaranteed access. Six out of the 26 countries in our sample guarantee a place in childcare.

- Childcare costs: Net childcare costs paid by single persons with two children for full-time centrebased childcare, expressed as a percentage of their disposable household income and after any benefits designed to reduce the gross childcare fees in 2008 (OECD, 2019a). The percentage of disposable household income ranges from $-9.0 \%$ to $32.0 \%$ with a mean of $8.5 \%$ and a standard deviation of $9.7 \%$ A higher score indicates higher childcare costs.

- Unemployment rate: We controlled for the number of unemployed people as a percentage of the labour force in 2010 (OECD, 2019c), because the risk of becoming NEET is higher in times of economic setbacks. The index we used has a mean of $9.6 \%$ and a standard deviation of $3.7 \%$ and it ranges from $4 \%$ to $20 \%$; a higher score indicates a higher level of unemployment within the country.

Table 2. Descriptive statistics on country-level variables

\begin{tabular}{|c|c|c|c|c|c|}
\hline & $\mathbf{N}$ & Mean & SD & Min. & Max. \\
\hline Paid parental leave duration & 26 & 10.1 & 6.5 & 3 & 24 \\
\hline Guaranteed childcare placement & 26 & 0.1 & 0.4 & 0 & 1 \\
\hline Childcare costs & 26 & 8.5 & 9.7 & -9 & 32 \\
\hline Unemployment rate & 27 & 9.6 & 3.7 & 4 & 20 \\
\hline
\end{tabular}

\section{METHODS}

To test our hypotheses, we used a multilevel approach that allows examination of cross-national variation in micro associations by correcting estimations and standard errors for the hierarchical structure (Snijders \& Bosker, 2012). In this case, we looked at young mothers who were clustered within countries. The likelihood that they use parental leave/ECEC or become NEET later in life is influenced by both individual and contextual characteristics. When we looked at the relation between the use of parental leave/ECEC and NEET later in life, we added a random slope to the models to allow the effect 
of using parental leave/ECEC to vary across countries. We expected that the group of young mothers who do and do not use parental leave/ECEC to be different from each other, and therefore have a different slope. Since our dependent variables are dichotomous, we used multilevel logistic regression. We estimated models using the melogit package in Stata 15. Additionally, we present margins plots about the results regarding the moderating effect of the use of parental leave/ECEC and family policies on NEET risks later in life. Firstly, because it makes the interpretation of the interaction effect more visually. Secondly, because it could show that parts of a relationship is significant (when the confidence intervals do not overlap) while this cannot be seen based on the single regression estimate. ${ }^{4}$ We present the margins plots consistently: on the x-axis we present the family policy, on the $y$-axis we present the outcome variable 'NEET later in life' and the lines that are shown within the graph display the categories of the use of parental leave/ECEC.

Next, we would like to pay attention to some methodological issues. First, , we understand that there could be a selection bias of women into motherhood based on the family policies offered within countries. However, when we compared different characteristics of mothers versus women without children we were not able to find a valid and strong instrument for motherhood that we could exploit as a source of exogenous variation. In addition, previous research on the impact of family policies on fertility has shown that the impact is small and varies highly based on the used data and type of family policies (See review: Gauthier, 2007). Since a convincingly causal relationship between family policies and fertility is not established yet, we expect no strong selection effect into motherhood across our sample. Second, we use cross-sectional data which makes it impossible to control for reverse causality. In this research we make an explanatory analysis without aiming for causal claims. We are able to establish relevant empirical evidence about how particular events could be linked to each other by looking at the 'causes of effects' rather than the 'effects of causes' (Goldthorpe, 2001). Also, we are not able to control for unobserved heterogeneity that might obscure the relation. Therefore, our aim is not to formally identify the causal impact of family policies. However, we distinguish between the different explanations for the relation between family policies and NEET risks among young mothers, which still determines the relative importance of our research questions. 


\section{RESULTS}

Before formally testing our hypotheses that focus on young mothers only, we first examined whether cross-national variation exists between countries in the relationship between young motherhood and NEET later in life. We performed an ordinary least square regression for each country and looked at the relation between young motherhood (age 20 to 29) and NEET later in life, net of the effect of age, education and migration background. ${ }^{5}$

Figure 3 shows the betas of the relation between motherhood and NEET later in life per country. We found that across Europe, young mothers are more likely to become NEET later in life than women without children. Except for Hungary, all the associations are significant under $\mathrm{p}<0.05$. In addition, we observed large cross-national variation. The weakest relationship between young mothers and the likelihood of becoming NEET later in life include Norway (6.0\%-point), Finland (6.0\%-point) and Slovenia (9.4\%-point). Countries with relatively strong associations between young motherhood and NEET later in life are Austria (31.7\%-point), Slovak Republic (33.7\%-point) and Germany (33.8\%point).

This shows that motherhood is an important determinant of NEETs, and one that substantially varies in strength across countries. This also motivates the importance of examining the family policy context as an institutional determinant of NEET across countries, and therefore we continued the analyses by using only young mothers. 


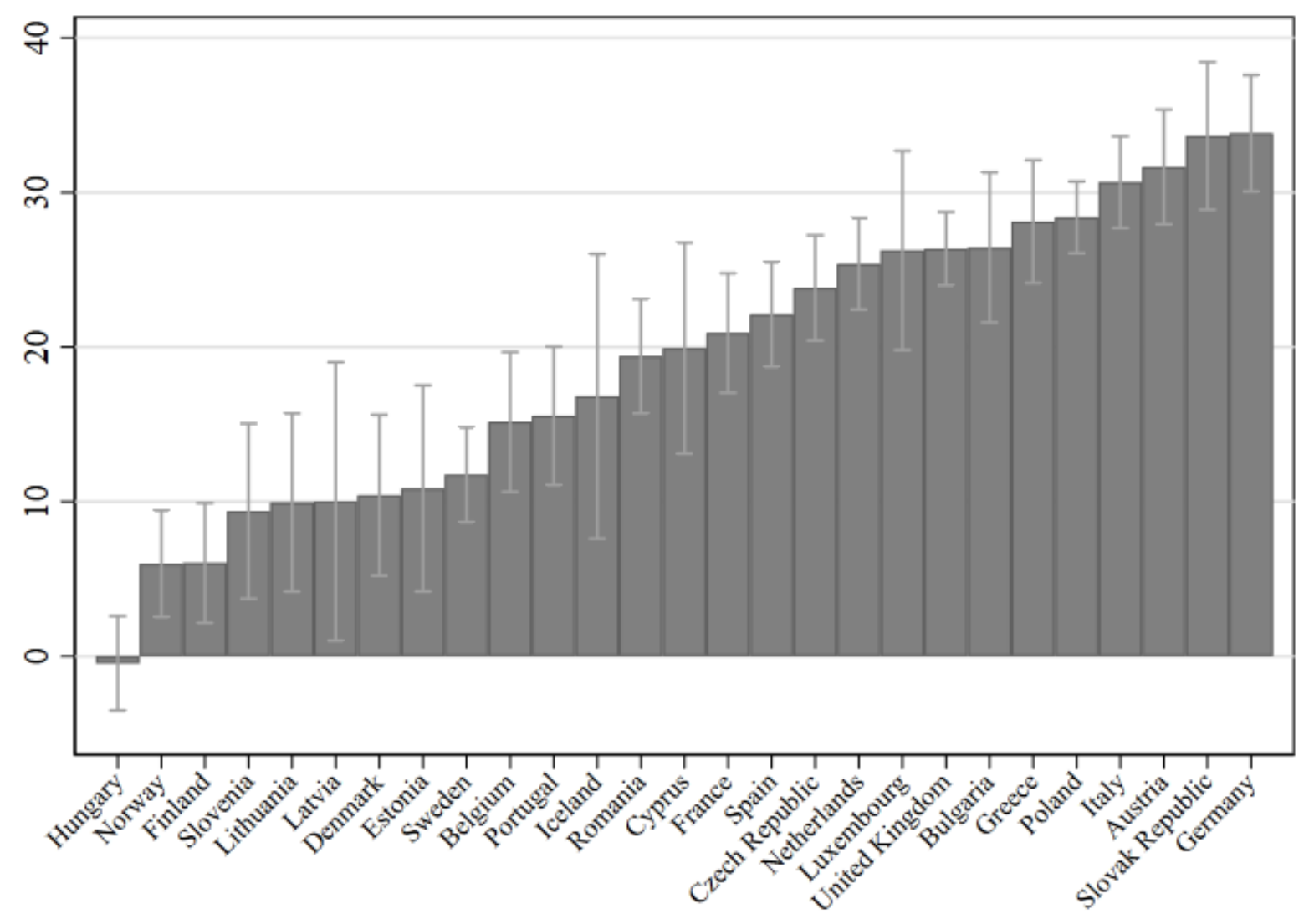

Figure 3. Association between motherhood and NEET later in life, controlled for age, education level and migration background

We organised the following part in the same order as the proposed hypotheses. First, we tested the hypotheses regarding parental leave, and second we tested the hypotheses regarding ECEC services. Table 3 and Table 5 show the results of the first stage related to the relationship between family policies and the use of parental leave/ECEC services. The second stage is related to the use of parental leave/ECEC services and the risk of becoming NEET later in life. The results can be found in Table 4 and Table 6. These tables also present the results of the third stage. We present all estimates in the tables as logits.

\section{PARENTAL LEAVE}

Table 3 presents the relation between the supported duration of paid parental leave by the state and the likelihood of young mothers using parental leave. Compared to Model 0 without any predictors, Model 
1 shows that after including the paid parental leave duration at the country level, the country variance decreased from 3.663 to 2.748 . This indicates that almost a quarter of the country variation in parental leave use can be explained by the duration of paid parental leave offered by the country.

According to Model 1 in Table 3, we found that the longer the access to paid parental leave, the more likely young mothers are to use it (0.987). Even when controlling for individual characteristics and the unemployment rate within a country, this association remained significant (Model 2: 0.933). Therefore, our findings are in line with Hypothesis 1a: Young mothers are more likely to use parental leave in countries that provide longer periods of paid parental leave compared to countries with shorter periods of paid leave.

Table 3. Multilevel logistic regression: estimates of the relation between family policies and use of parental leave (logits)

\begin{tabular}{|c|c|c|c|}
\hline & Mo & M1 & M2 \\
\hline Paid parental leave duration & & $\begin{array}{l}0.987 * * \\
(0.339)\end{array}$ & $\begin{array}{l}0.933 * * \\
(0.334)\end{array}$ \\
\hline \multicolumn{4}{|l|}{ Control variables: } \\
\hline Use of ECEC ( $\mathrm{No}=$ ref.) & & & $\begin{array}{l}0.151^{* *} \\
(0.050)\end{array}$ \\
\hline \multicolumn{4}{|l|}{ Education level (Low=ref.) } \\
\hline Medium & & & $\begin{array}{l}0.663 * * * \\
(0.059)\end{array}$ \\
\hline High & & & $\begin{array}{l}0.572 * * * \\
(0.074)\end{array}$ \\
\hline \multicolumn{4}{|l|}{ Age (Age 20-24=ref.) } \\
\hline Age $25-29$ & & & $\begin{array}{l}0.394 * * * \\
(0.055)\end{array}$ \\
\hline \multicolumn{4}{|l|}{ Migration background (Native=ref.) } \\
\hline Foreigner from Europe & & & $\begin{array}{l}-0.569 * * * \\
(0.098)\end{array}$ \\
\hline Foreigner from outside Europe & & & $\begin{array}{l}-0.567 \text { *** } \\
(0.129)\end{array}$ \\
\hline Unemployment rate & & & $\begin{array}{l}0.220 \\
(0.299)\end{array}$ \\
\hline Constant & $\begin{array}{l}-0.664 \sim \\
(0.376)\end{array}$ & $\begin{array}{l}-0.932 * * \\
(0.340)\end{array}$ & $\begin{array}{l}-1.675^{* * *} \\
(0.339)\end{array}$ \\
\hline Country variance & $\begin{array}{l}3.663 * * * \\
(1.082)\end{array}$ & $\begin{array}{l}2.748 * * * \\
(0.813)\end{array}$ & $\begin{array}{l}2.629 * * * \\
(0.779)\end{array}$ \\
\hline $\mathrm{N}$ country & 26 & 26 & 26 \\
\hline $\mathrm{N}$ individual & 13,510 & 13,510 & 13,510 \\
\hline
\end{tabular}

$\sim p<0.10, * p<0.05, * * p<0.01, * * * p<0.001$; Standard errors in parentheses; Iceland is excluded from analyses because of missing data on paid parental leave duration 
The second stage focuses on the relation between the use of parental leave and the subsequent risk of becoming NEET later in life. Table 4 presents the results from the logistic multilevel regression analyses.

Models 1 to 3 show that young mothers who took at least one month of parental leave are less likely to become NEET later in life compared to young mothers who took less than one month of parental leave (-1.411/-1.263). However, since literature has shown a curvilinear relationship between the length of parental leave and the labour market attachment, we also explored whether this curvilinear relationship exists in our sample. According to Models 5 and 6, shorter leave (up to three months) increased the likelihood of becoming NEET later in life compared to using three to twelve months of leave (0.809/0.835). Additionally, an overly long use of parental leave (more than one year) also increased the likelihood of becoming NEET later in life compared to young mothers who use three to twelve months of leave $(0.266 / 0.291)$. These findings support the claim that a short or overly long period of parental leave could be problematic (Akgunduz \& Plantenga, 2012; Del Boca et al., 2008; Nieuwenhuis et al., 2017; Thévenon \& Solaz, 2014). Based on these results, our findings support Hypothesis 1b: Young mothers who use parental leave are less likely to become NEET later in life than young mothers who do not use parental leave, but young mothers who use overly short or overly long periods of parental leave are more likely to become NEET later in life than young mothers who use a moderate period of parental leave.

For the third stage, we expected a moderating role of the duration of paid parental leave on the relation between the individual parental leave use and the subsequent NEET risks later in life. Model 2 shows that the higher the paid parental leave within a state, the more likely young mothers are to become NEET later in life (0.300). Model 3 reveals that the differences between young mothers who used at least one month of parental leave and young mothers who did not use any parental leave were larger in countries with longer periods of paid parental leave (-0.503). Figure 4 shows this result in a margins plot. Here we see that the differences between the non-users and users of parental leave are smaller in countries with low durations of paid parental leave. However, these differences become larger as countries support longer periods of paid parental leave. This could indicate that in countries with long periods of paid parental leave, those who used less than 1 month of parental leave have an excessive 
distance to the labour market and therefore are more likely to become NEET later in life. Other factors also seem to play a role, such as voluntary homemaking and disabilities. Nevertheless, Hypothesis 1c can be supported: In countries with longer availability of paid parental leave, young mothers who use parental leave are better protected against NEET risks later in life than in countries with shorter periods of paid parental leave.

In Model 7 we interacted the individual use of leave with the duration of paid leave as contained in the (national-level) leave policy. With respect to the length of parental leave use at the individual level, we did not find a moderating effect with the duration of paid parental leave if we look at Table 4, Model 7. However, according to the margins plot presented in Figure 5 we can make a different conclusion. We find that the confidence intervals of the length of parental leave up to three months does not overlap with the confidence intervals of the length of parental leave between three and twelve months in countries with an average paid parental leave duration of between approximately $1(-1,5$ standard deviation from mean) and 23 months ( 2 standard deviations from mean). This indicates that young mothers who use up to three months of parental leave but lived in countries with an average period of paid parental below 23 months were significantly more likely to become NEET later in life than mothers who used longer periods of parental leave. In other words: young mothers who take less than 3 months of parental leave are at more of a disadvantage in comparison to mothers who take 3 to 12 months of parental leave, independent of the paid parental leave duration within a country.

However, our in our hypothesis we are especially interested in young mothers with overly long parental leave us, thus more than one year of parental leave use. When we look at the difference between young mothers who used up to 3 months of parental leave and young mothers who used more than one year of parental leave, it seems that young mothers who used up to 3 months of parental leave but lived in countries with an average or longer period of paid parental leave - approximately between 10 months (mean) and 23 months (2 standard deviations from mean) - were significantly more likely to become NEET later in life than mothers who used more than one year parental leave. This indicates that in countries with an average or longer period of paid parental leave, young mothers who take less than 3 months of parental leave are at more of a disadvantage compared to young mothers who take more than 
one year of parental leave. This is in line with our expectation (because the young mothers with long leave within a country that supports a long duration of paid parental leave are not more likely to become NEET later in life), since it only holds for countries that support an average or longer than average period of paid parental leave. Therefore, our findings are in line with Hypothesis 1d: In countries with longer availability of paid parental leave, young mothers who take overly long periods of parental leave are better protected against NEET risks later in life than in countries with shorter periods of paid parental leave (but only for countries with an average or longer than average period of paid parental leave). 
Table 4. Multilevel logistic regression: estimates of the relation between parental leave use and NEET risks later in life (logits)

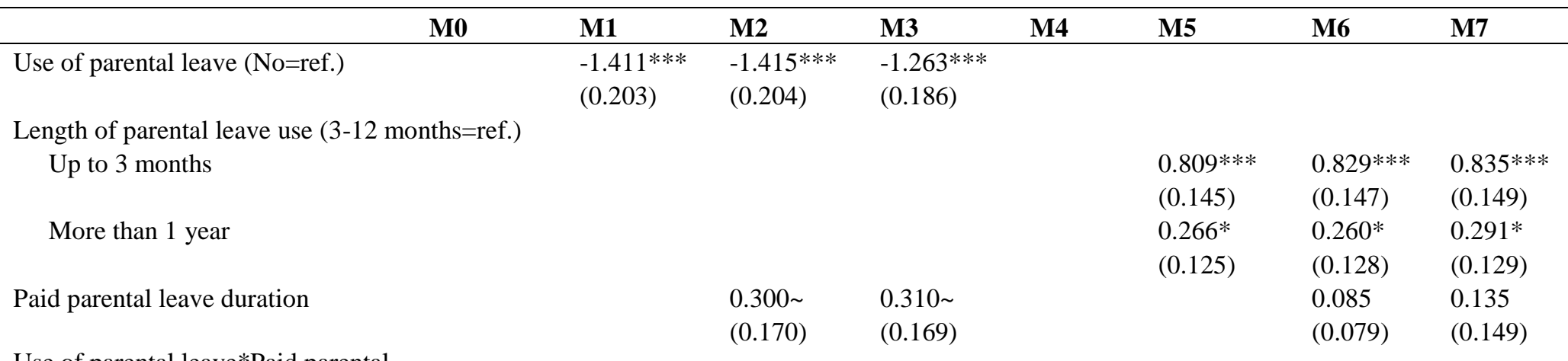

Use of parental leave*Paid parental

leave duration

$-0.503 * *$

(0.178)

Interaction length of parental leave use*Paid parental leave duration

Up to 3 months*Paid parental leave duration

0.036

(0.163)

$-0.123$

More than 1 year*Paid parental leave duration

Control variables:

Use of ECEC (No=ref.)

Education level (Low=ref.)

Medium

High

Age (Age 20-24=ref.)

Age 25-29

Migration background (Native=ref.)

Foreigner from Europe

Foreigner from outside Europe

Unemployment rate

Constant

Slope variance use of parental leave

(0.146)

$-0.770 * * *$

$-0.969 * * *$

$-0.970 * * *$

$-0.970 * * *$

(0.049)

$(0.049)$

(0.049)

$-0.709 * * *$

$-0.709 * * *$

$-0.708 * * *$

$(0.050)$

$(0.050)$

(0.050)

-1.310 ***

$-1.310^{* * *}$

$-1.308 * * *$

(0.069)

(0.069)

(0.069)

$-0.238 * * * \quad-0.237 * * * \quad-0.237 * * *$

$\begin{array}{lll}(0.049) & (0.049) \quad(0.049)\end{array}$

$0.399 * * * \quad 0.402 * * * \quad 0.404 * * *$

(0.078)

$0.474 * * *$

(0.078)

(0.077)

(0.090)

$0.477 * * *$

$0.478 * * *$

0.083

(0.090)

(0.090)

(0.163)

0.050

0.059

(0.156)

(0.155)

$0.876 * * *$

$0.798 * * *$

$0.803 * * *$

(0.178)

(0.177)

$(0.182)$

$0.863^{* *}$

$0.614 * *$

(0.283)

(0.283)

(0.211)

Slope variance length of parental leave up to 3 months

Slope variance length of parental leave more than 1 year

Country variance

$\mathrm{N}$ country

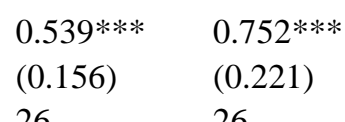

$0.667 * * *$

$0.659 * * *$

(0.197)

(0.195)

$26 \quad 26$

$\mathrm{N}$ individual

13,510

13,510

26

26

13,510

13,510

$\sim p<0.10, * p<0.05, * * p<0.01, * * * p<0.001 ;$ Standard errors in parentheses; Iceland is excluded from

analyses because of missing data on paid parental leave duration; the number of individuals is lower in Models

4-7 because we left out young mothers who are still on parental leave 


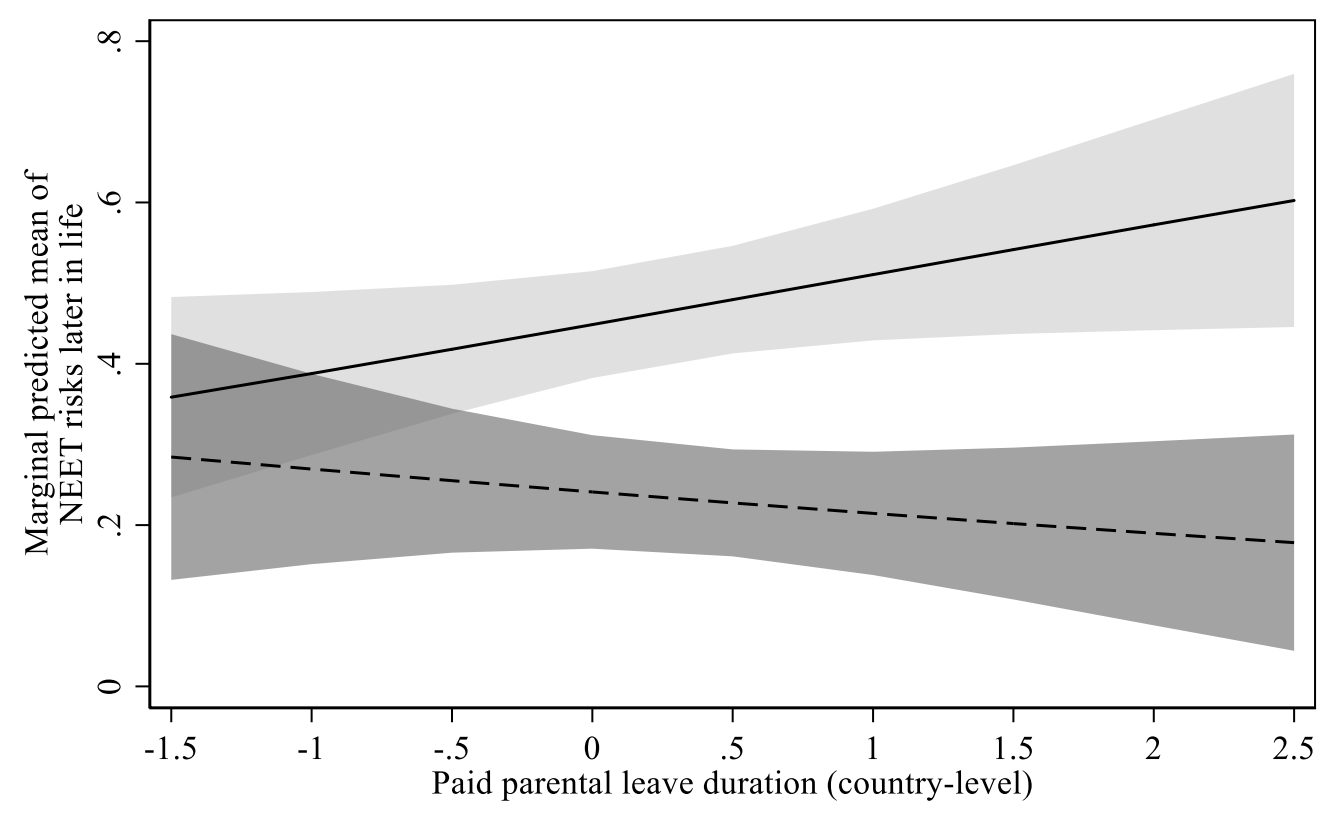

Use of parental leave

No ----- Yes

Figure 4. Margins plot of the interaction between the use of parental leave and the paid parental leave duration supported by the state (Table 4, Model 3)

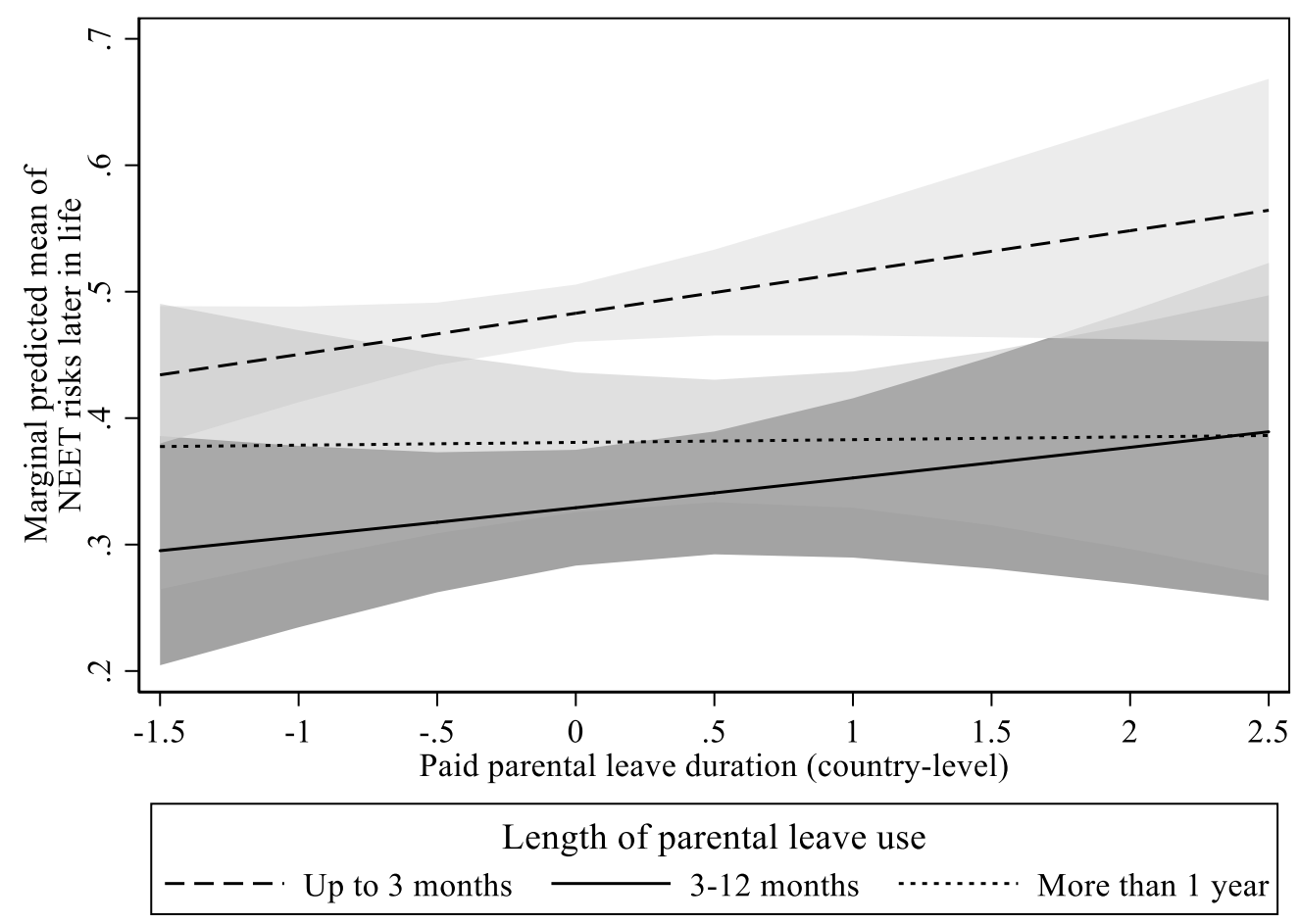

Figure 5. Margins plot of the interaction between the length of parental leave use and the paid parental leave duration supported by the state (Table 4, Model 7) 


\section{ECEC}

This part of the analysis focuses on ECEC services. In accordance with the first stage, we were interested in how policy implications related to the availability and affordability of ECEC services increase young mothers' use of those services. Table 5 shows the results.

Model 0 and Model 1 show that after including the family policy about the guaranteed placement in childcare, the country variance decreased from 0.421 to 0.296 . This means that almost one third of the country variation in the use of ECEC services can be attributed to family policies that guarantee placement in childcare. With regard to the family policies related to the costs of childcare, we barely found a difference in country variance between Model 3 (0.447) and Model 4 (0.442).

In accordance with our first stage expectations, Model 1 shows that in countries where the state guarantees a place in childcare, young mothers are more likely to use ECEC services (Model 1: 0.844). After controlling for the use of parental leave, education level, age, migration background and the unemployment rate within the country, the result remained significant (Model 2: 0.775). We did not find a significant relation between the costs of childcare and the use of ECEC services among young mothers (Models 4 and 5).

These results support Hypothesis 2a: Young mothers are more likely to use ECEC services in countries where ECEC is guaranteed compared to countries where ECEC is not guaranteed. 
Table 5. Multilevel logistic regression: estimates of the relation between family policies and use of ECEC (logits)

\begin{tabular}{|c|c|c|c|c|c|c|}
\hline & Mo & M1 & M2 & M3 & M4 & M5 \\
\hline $\begin{array}{l}\text { Guaranteed childcare placement } \\
\text { (No=ref.) }\end{array}$ & & $\begin{array}{l}0.844 * * \\
(0.260)\end{array}$ & $\begin{array}{l}0.775^{* *} \\
(0.254)\end{array}$ & & & \\
\hline Childcare costs & & & & & $\begin{array}{l}0.025 \\
(0.144)\end{array}$ & $\begin{array}{l}0.037 \\
(0.142)\end{array}$ \\
\hline \multicolumn{7}{|l|}{ Control variables: } \\
\hline Use of parental leave ( $\mathrm{No}=$ ref.) & & & $\begin{array}{l}0.149 * * \\
(0.050)\end{array}$ & & & $\begin{array}{l}0.154 * * \\
(0.050)\end{array}$ \\
\hline \multicolumn{7}{|l|}{ Education level (Low=ref.) } \\
\hline Medium & & & $\begin{array}{l}0.153 * * \\
(0.049)\end{array}$ & & & $\begin{array}{l}0.138^{* *} \\
(0.049)\end{array}$ \\
\hline High & & & $\begin{array}{l}0.130^{*} \\
(0.062)\end{array}$ & & & $\begin{array}{l}0.119 \sim \\
(0.062)\end{array}$ \\
\hline \multicolumn{7}{|l|}{ Age (Age 20-24=ref.) } \\
\hline Age 25-29 & & & $\begin{array}{l}0.515^{* * * *} \\
(0.050)\end{array}$ & & & $\begin{array}{l}0.524 * * * \\
(0.050)\end{array}$ \\
\hline \multicolumn{7}{|l|}{$\begin{array}{l}\text { Migration background } \\
\text { (Native=ref.) }\end{array}$} \\
\hline Foreigner from Europe & & & $\begin{array}{l}-0.030 \\
(0.074)\end{array}$ & & & $\begin{array}{l}-0.046 \\
(0.075)\end{array}$ \\
\hline Foreigner from outside Europe & & & $\begin{array}{l}-0.130 \\
(0.086)\end{array}$ & & & $\begin{array}{l}-0.156 \sim \\
(0.087)\end{array}$ \\
\hline Unemployment rate & & & $\begin{array}{l}-0.151 \\
(0.099)\end{array}$ & & & $\begin{array}{l}-0.190 \\
(0.123)\end{array}$ \\
\hline Constant & $\begin{array}{l}-0.587 * * * \\
(0.129)\end{array}$ & $\begin{array}{l}-0.782 * * * \\
(0.124)\end{array}$ & $\begin{array}{l}-1.334 * * * \\
(0.132) \\
\end{array}$ & $\begin{array}{l}-0.558 * * * \\
(0.133)\end{array}$ & $\begin{array}{l}-0.558^{* * * *} \\
(0.133)\end{array}$ & $\begin{array}{l}-1.118^{* * * *} \\
(0.138)\end{array}$ \\
\hline Country variance & $\begin{array}{l}0.421 * * * \\
(0.121)\end{array}$ & $\begin{array}{l}0.296^{* * * *} \\
(0.086)\end{array}$ & $\begin{array}{l}0.281 * * * \\
(0.082)\end{array}$ & $\begin{array}{l}0.447 * * * \\
(0.129)\end{array}$ & $\begin{array}{l}0.447 * * * \\
(0.128)\end{array}$ & $\begin{array}{l}0.414 * * * \\
(0.120)\end{array}$ \\
\hline $\mathrm{N}$ country & 26 & 26 & 26 & 26 & 26 & 26 \\
\hline $\mathrm{N}$ individual & 13,510 & 13,510 & 13,510 & 13,428 & 13,428 & 13,428 \\
\hline
\end{tabular}

For the second stage, we looked at the relation between the use of ECEC services by young mothers and their subsequent NEET risks later in life. Across all models in Table 6, we found that the use of ECEC decreases the likelihood of becoming NEET later in life (-0.956/-0.959). This corroborates with Hypothesis 2c: Young mothers who use ECEC services are less likely to become NEET later in life compared to young mothers who do not use ECEC services.

Regarding the third stage of the process, we tested whether family policies regarding the use of ECEC would also moderate the relationship between the use of ECEC services and the chance of becoming NEET later in life. We expected that family policies that increase the availability or affordability of ECEC services would enhance the negative relationship between the use of ECEC 
services and the likelihood of becoming NEET later in life. However, as Table 6 reveals, none of the aspects of the ECEC-related family policies and relating interactions showed a significant result. Nonetheless, a closer examination of the margins plot belonging to the interaction of Model 3 reveals that in countries that do not guarantee a placement in childcare, the differences between the young mothers who use ECEC services and those who do not use ECEC services are significant (Figure 6). However, we should be careful about interpreting this result, since only six out of 26 countries guaranteed a place in childcare and the two lines do not seem to diverge or converge. Therefore, our findings are inconsistent with Hypothesis 2d.

In Figure 7, which represents the interaction of Model 7, we also found some significant differences between young mothers living in countries where the net childcare costs were less than $23.8 \%$ ( 1 standard deviation above mean) of the disposable household income. In these countries, the users of ECEC services had a significantly lower likelihood of becoming NEET later in life than the young mothers who did not use ECEC services. This could indicate that in countries where childcare costs are relatively high, young mothers are less likely to use ECEC services and therefore this aspect of family policy is less effective. Thus, Hypothesis $2 \mathrm{e}$ is supported: In countries where ECEC is more affordable, young mothers who use ECEC are better protected against NEET risks later in life than in countries where ECEC is less affordable. 
Table 6. Multilevel logistic regression: estimates of the relation between childcare use and NEET risks later in life (logits)

\begin{tabular}{|c|c|c|c|c|c|c|c|c|}
\hline & Mo & M1 & M2 & M3 & M4 & M5 & M6 & M7 \\
\hline Use of ECEC ( $\mathrm{No}=$ ref.) & & $\begin{array}{l}-0.956 * * * \\
(0.122)\end{array}$ & $\begin{array}{l}-0.954 * * * \\
(0.122)\end{array}$ & $\begin{array}{l}-0.978 * * * \\
(0.138)\end{array}$ & & $\begin{array}{l}-0.959 * * * \\
(0.123)\end{array}$ & $\begin{array}{l}-0.958 * * * \\
(0.123)\end{array}$ & $\begin{array}{l}-0.958 * * * \\
(0.123)\end{array}$ \\
\hline Guaranteed childcare placement ( $N$ & $o=$ ref.) & & $\begin{array}{l}-0.157 \\
(0.336)\end{array}$ & $\begin{array}{l}-0.168 \\
(0.337)\end{array}$ & & & & \\
\hline Use of ECEC*Guaranteed childcar & placement & & & $\begin{array}{l}0.109 \\
(0.295)\end{array}$ & & & & \\
\hline Childcare costs & & & & & & & $\begin{array}{l}-0.171 \\
(0.153)\end{array}$ & $\begin{array}{l}-0.172 \\
(0.154)\end{array}$ \\
\hline Use of ECEC*Childcare costs & & & & & & & & $\begin{array}{l}0.008 \\
(0.136)\end{array}$ \\
\hline \multicolumn{9}{|l|}{ Control variables: } \\
\hline Use of parental leave ( $\mathrm{No}=$ ref.) & & $\begin{array}{l}-1.629 * * * \\
(0.056)\end{array}$ & $\begin{array}{l}-1.628 * * * \\
(0.056)\end{array}$ & $\begin{array}{l}-1.627 * * * \\
(0.056)\end{array}$ & & $\begin{array}{l}-1.629 * * * \\
(0.056)\end{array}$ & $\begin{array}{l}-1.627 * * * \\
(0.056)\end{array}$ & $\begin{array}{l}-1.627 * * * \\
(0.056)\end{array}$ \\
\hline \multicolumn{9}{|l|}{ Education level (Low=ref.) } \\
\hline Medium & & $\begin{array}{l}-0.689 * * * \\
(0.049)\end{array}$ & $\begin{array}{l}-0.689 * * * \\
(0.049)\end{array}$ & $\begin{array}{l}-0.689 * * * \\
(0.049)\end{array}$ & & $\begin{array}{l}-0.697 * * * \\
(0.049)\end{array}$ & $\begin{array}{l}-0.696^{* * * *} \\
(0.049)\end{array}$ & $\begin{array}{l}-0.696 * * * \\
(0.049)\end{array}$ \\
\hline High & & $\begin{array}{l}-1.258^{* * *} \\
(0.069)\end{array}$ & $\begin{array}{l}-1.258^{* * * *} \\
(0.069)\end{array}$ & $\begin{array}{l}-1.258^{* * *} \\
(0.069)\end{array}$ & & $\begin{array}{l}-1.273 * * * \\
(0.069)\end{array}$ & $\begin{array}{l}-1.271 * * * \\
(0.069)\end{array}$ & $\begin{array}{l}-1.271^{* * *} \\
(0.069)\end{array}$ \\
\hline \multicolumn{9}{|l|}{ Age (Age 20-24=ref.) } \\
\hline Age 25-29 & & $\begin{array}{l}-0.242 * * * \\
(0.048)\end{array}$ & $\begin{array}{l}-0.242 * * * \\
(0.048)\end{array}$ & $\begin{array}{l}-0.242 * * * \\
(0.048)\end{array}$ & & $\begin{array}{l}-0.237 * * * \\
(0.049)\end{array}$ & $\begin{array}{l}-0.237 * * * \\
(0.049)\end{array}$ & $\begin{array}{l}-0.237 * * * \\
(0.049)\end{array}$ \\
\hline \multicolumn{9}{|l|}{$\begin{array}{l}\text { Migration background } \\
\text { (Native=ref.) }\end{array}$} \\
\hline Foreigner from Europe & & $\begin{array}{l}0.412 * * * \\
(0.077)\end{array}$ & $\begin{array}{l}0.412 * * * \\
(0.077)\end{array}$ & $\begin{array}{l}0.412 * * * \\
(0.077)\end{array}$ & & $\begin{array}{l}0.396 * * * \\
(0.078)\end{array}$ & $\begin{array}{l}0.396 * * * \\
(0.078)\end{array}$ & $\begin{array}{l}0.396 * * * \\
(0.078)\end{array}$ \\
\hline Foreigner from outside Europe & & $\begin{array}{l}0.463 * * * \\
(0.090)\end{array}$ & $\begin{array}{l}0.463 * * * \\
(0.090)\end{array}$ & $\begin{array}{l}0.463 * * * \\
(0.090)\end{array}$ & & $\begin{array}{l}0.455^{* * *} \\
(0.092)\end{array}$ & $\begin{array}{l}0.454 * * * \\
(0.092)\end{array}$ & $\begin{array}{l}0.454 * * * \\
(0.092)\end{array}$ \\
\hline Unemployment rate & & $\begin{array}{l}0.132 \\
(0.131)\end{array}$ & $\begin{array}{l}0.129 \\
(0.130)\end{array}$ & $\begin{array}{l}0.129 \\
(0.130)\end{array}$ & & $\begin{array}{l}0.132 \\
(0.132)\end{array}$ & $\begin{array}{l}0.163 \\
(0.132)\end{array}$ & $\begin{array}{l}0.163 \\
(0.132)\end{array}$ \\
\hline Constant & $\begin{array}{l}-0.770 * * * \\
(0.146)\end{array}$ & $\begin{array}{l}0.865^{* * *} \\
(0.149) \\
\end{array}$ & $\begin{array}{l}0.900 * * * \\
(0.166) \\
\end{array}$ & $\begin{array}{l}0.901 * * * \\
(0.166)\end{array}$ & $\begin{array}{l}-0.778 * * * \\
(0.146)\end{array}$ & $\begin{array}{l}0.867 * * * \\
(0.150) \\
\end{array}$ & $\begin{array}{l}0.866 * * * \\
(0.147) \\
\end{array}$ & $\begin{array}{l}0.865^{* * *} \\
(0.147) \\
\end{array}$ \\
\hline Slope variance use of ECEC & & $\begin{array}{l}0.295^{* *} \\
(0.105)\end{array}$ & $\begin{array}{l}0.296 * * \\
(0.106)\end{array}$ & $\begin{array}{l}0.294 * * \\
(0.105)\end{array}$ & & $\begin{array}{l}0.299 * * \\
(0.107)\end{array}$ & $\begin{array}{l}0.299 * * \\
(0.107)\end{array}$ & $\begin{array}{l}0.299 * * \\
(0.107)\end{array}$ \\
\hline Country variance & $\begin{array}{l}0.539 * * * \\
(0.156)\end{array}$ & $\begin{array}{l}0.485 * * * \\
(0.146)\end{array}$ & $\begin{array}{l}0.481 * * * \\
(0.144)\end{array}$ & $\begin{array}{l}0.481 * * * \\
(0.144)\end{array}$ & $\begin{array}{l}0.540 * * * \\
(0.157)\end{array}$ & $\begin{array}{l}0.489 * * * \\
(0.147)\end{array}$ & $\begin{array}{l}0.466 \text { *** } \\
(0.140)\end{array}$ & $\begin{array}{l}0.466 * * * \\
(0.140)\end{array}$ \\
\hline $\mathrm{N}$ country & 26 & 26 & 26 & 26 & 26 & 26 & 26 & 26 \\
\hline $\mathrm{N}$ individual & 13,510 & 13,510 & 13,510 & 13,510 & 13,428 & 13,428 & 13,428 & 13,428 \\
\hline
\end{tabular}

$\sim p<0.10, * p<0.05, * * p<0.01, * * * p<0.001$; Standard errors in parentheses; Iceland is excluded from Models 0-3 and Cyprus from Model 4-7 because of missing data on the related family policy 




Figure 6. Margins plot interaction use of ECEC services and guaranteed childcare placement by the state (Table 6, Model 3)

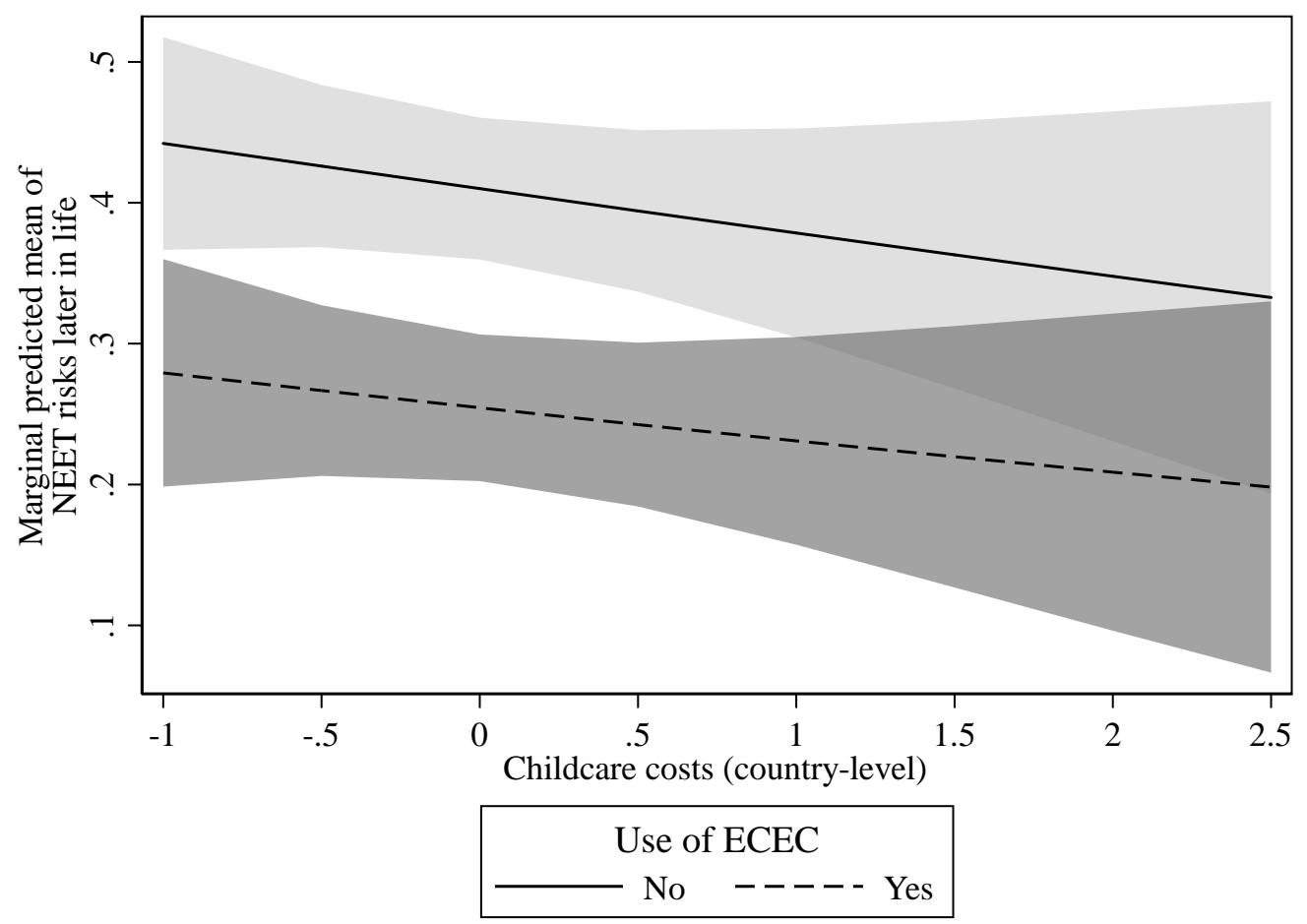

Figure 7. Margins plot of the interaction between the use of ECEC services and the costs of childcare (Table 6, Model 7) 


\section{ALTERNATIVE TESTS}

We conducted several sensitive tests in which we tested whether our results remained stable. For example, we included young mothers aged 16-19 (see Appendix, Table A4-A7), we kept the number of countries equal across all analyses by leaving out Cyprus and Iceland (see Appendix, Table A8-A11), we did not control for the use of ECEC services for the analyses about the use of parental leave (see Appendix, Table A12-A13), and we did not control for the use of parental leave for the analyses about the use of ECEC services (see Appendix, Table A14-A15). Lastly, we checked whether our results remained the same when we took a random sample of $50 \%$ of young mothers per country (see Appendix, Table A16-19) and when we used macro-data from 2004 rather than 2008/2009 (see Appendix Tables A20-A23). For all these alternative tests, we found that our substantive conclusions remained the same.

\section{CONCLUSIONS AND DISCUSSION}

This paper explored the process of young mothers becoming NEET, and the role family policies play in this process. Motherhood proves to be an important determinant of NEET among young women, as was their use of family policy. This was as of yet unexplored in the literature. We used data from the EU-LFS, containing 13,581 young mothers aged 20-29 from 27 European Union countries with a child up to the age of 8 living in the household. Using logistic multilevel designs, we examined whether aspects of family policies are relevant to understanding the relationship between the use of parental leave and ECEC services and NEET later in life.

We focused on two specific family policies designed to reconcile work and family: support for parental leave benefits and support for public services for early childhood education and care (ECEC). The first enables mothers to temporarily disengage from the labour market to care for their children, while the latter facilitates combining motherhood with employment, training or enrolment in education.

To disentangle the process of mothers becoming NEET later in life - in relation to family policies - we analysed the process that leads to young mothers becoming NEET in three stages. In the first stage, we analysed whether family policies were related to the use of parental leave and ECEC services among young mothers. We found that the longer a country supported the use of paid parental leave, the more likely women were to use parental leave. Also, if countries guaranteed a place in 
childcare, young mothers were more likely to use ECEC services. However, we did not find a significant relation between lower costs of childcare services at the country level and the use of ECEC services. Here, individual determinants seemed to better predict the use of ECEC services.

In the second stage, we explored the relationship between the use of parental leave and ECEC services on the likelihood of becoming NEET later in life. We found that young mothers who took at least one month of parental leave were less likely to become NEET later in life. In addition, we found that young mothers who took a short or overly long period of parental leave were more likely to become NEET compared to young mothers who took a parental leave of between three and twelve months. Also, we found that young mothers who used ECEC services were less likely to become NEET later in life compared to young mothers who did not use ECEC services. This might indicate that the use of parental leave and ECEC services are factors that help maintain the labour market or education attachment and therefore decreases the likelihood of these young mothers becoming NEET later in life. However, an overly long or overly short period of parental leave has a negative impact on the likelihood of becoming NEET later in life.

In the third stage, we studied whether family policies moderated the relationship between the use of parental leave and ECEC services on NEET later in life. Here, the results were less clear. We found that in countries with longer paid durations of parental leave, the relationship between the actual use of parental leave and the probability of becoming NEET later in life was weaker. This could indicate that the more months of state support, the less likely it is that young mothers who use parental leave become NEET later in life, and the more likely it is that young mothers who do not use parental leave become NEET later in life. To account for the curvilinear effect, we examined this moderating relationship for the length of parental leave use as well, and found that overly long parental leave is less positively associated with the risk of becoming NEET later in life, but only for countries with an average or longer than average period of paid parental leave.

With respect to the family policies regarding ECEC use, we focused on the guarantee of a place in childcare and childcare costs. We found that in countries that did not guarantee a placement in childcare, the likelihood of becoming NEET later in life differed significantly between young mothers wo do and those who do not use ECEC services. However, we found no significant evidence for 
countries that guaranteed a placement in childcare. In addition, we found that in countries with low childcare costs, users of ECEC services were better protected against NEET risks later in life compared to non-users. We did not find this in countries with higher childcare costs.

Our analyses offer meaningful and theoretically innovative explanations about the extent to which the use of parental leave or ECEC services are associated with becoming NEET later in life, but future research can improve these findings by using more elaborate data. For example, the EU-LFS only included this specific ad hoc module in 2010. In 2005 they also collected data on the reconciliation on family and work, but these two ad hoc modules were not comparable. Because of this limitation, we could only analyse the data of 2010, while a comparison with 2005 , or a panel survey, would provide more in-depth information about the use of parental leave and ECEC services in relation to the timing of becoming NEET (even before childbirth, immediately after childbirth or years later). Future studies could enhance this research by looking at the causal relationships.

Our research shows that among women, young mothers are more likely to become NEET later in life. By focusing only on young mothers, we could test relevant family policies that are especially important for them. The results were clear regarding what aspects of family policies facilitate the use of paid leave and ECEC, and they demonstrate that actually taking leave (except when taking it for an overly short or long period) or ECEC helps protect young mothers against the risk of becoming NEET later in life. However, it seems that policies that increase the use of parental leave or ECEC services do not always have the desired effect. For example, while lowering the cost of childcare should increase the likelihood of people using ECEC services, our data show this is not always the case. It seems that other determinants, such as age and education, are better predictors of the use of ECEC services. Regardless of background characteristics, other reasons could be related to the low level of use even when costs of childcare are relatively low. For instance, if the costs of childcare are relatively low, but the quality is not good, young mothers may be more likely to stay at home or decide to use other kinds of (informal) childcare options (Yerkes \& Javornik, 2018). Future research could focus on this interplay between different (aspects of) family policies.

We have been able to demonstrate a novel set of individual and institutional determinants of NEET. As such, our analyses offer meaningful outcomes for future policy. Policies regarding NEETs 
are mostly policies targeted at young individuals and focused on their (re-)engagement in the labour market or education. However, in order to effectively reintegrate NEETs, policy makers should focus on the different needs and characteristics among them, and consider gender, motherhood and family policies as an integral part of their policies to prevent NEET risks.

\footnotetext{
${ }^{1}$ This figure is based on our own calculations from the EU-LFS 2010, more detailed information about the dataset can be found in the data-section. See Appendix A1 for an overview of the frequency table belonging to Figure 1.

${ }^{2}$ Although parental leave can be supplementary to maternity leave and/or paternity leave and is available for both parents, it is predominantly used by mothers (Karu \& Tremblay, 2018; Moss \& Deven, 2015; OECD, 2011).

${ }^{3}$ We limited the sample to young mothers aged 20-29, because until 19 most young people are in compulsory education (OECD, 2018).

${ }^{4}$ However, when intervals do not overlap, this does not necessarily mean that they are not significantly different (Knezevic, 2008).

${ }^{5}$ See Appendix Table A3 for OLS coefficients, standard errors and confidence intervals per country.
} 


\section{REFERENCES}

Akgunduz, Y. E., \& Plantenga, J. (2012). Labour market effects of parental leave in Europe. Cambridge Journal of Economics, 37(4), 845-862.

Becker, G. S. (1965). A Theory of the Allocation of Time. The Economic Journal, 75(299), 493-517.

Becker, G. S. (1981). A treatise on the family. Cambridge, MA: Harvard University Press.

Boeckmann, I., Misra, J., \& Budig, M. J. (2014). Cultural and institutional factors shaping mothers' employment and working hours in postindustrial countries. Social Forces, 93(4), 1301-1333.

Bynner, J., \& Parsons, S. (2002). Social exclusion and the transition from school to work: The case of young people not in education, employment, or training (NEET). Journal of vocational behavior, 60(2), 289-309. doi:10.1006/jvbe.2001.1868

Carcillo, S., Fernández, R., Königs, S., \& Minea, A. (2015). NEET Youth in the Aftermath of the Crisis: Challenges and Policies. OECD Social, Employment and Migration Working Papers, no. 164.

Del Boca, D., Pasqua, S., \& Pronzato, C. (2008). Motherhood and market work decisions in institutional context: a European perspective. Oxford Economic Papers, 61, 147-171.

Den Dulk, L., Peters, P., \& Poutsma, E. (2012). Variations in adoption of workplace work-family arrangements in Europe: The influence of welfare-state regime and organizational characteristics. The International Journal of Human Resource Management, 23(13), 27852808

Eurofound. (2012). NEETs - Young people not in employment, education or training: Characteristics, costs and policy responses in Europe. Luxembourg: Publications Office of the European Union

Eurofound. (2013). Caring for children and dependants: effect on careers of young workers. Background paper. Dublin: Eurofound.

Eurofound. (2016). Exploring the diversity of NEETs. Luxembourg: Publications Office of the European Union.

Eurofound. (2017). Living and working in Europe 2016. Luxembourg: Publications Office of the European Union. 
European Commission. (2010). Proposal for a Council Decision on guidelines for the employment policies of the Member States - Part II of the Europe 2020 Integrated Guidelines. Brussels: European Commission.

Gambaro, L., Stewart, K., \& Waldfogel, J. (2015). A question of quality: Do children from disadvantagedbackgrounds receive lower quality early years educationand care in England? British Educational Research Journal, 41(4), 553-574.

Gauthier, A. H. (2007). The impact of family policies on fertility in industrialized countries: a review of the literature. Population Research and Policy Review, 26(3), 323-346.

Goldthorpe, J. H. (2001). Causation, Statistics and Sociology. European Sociological Review, 17(1), 120.

Gornick, J. C., \& Meyers, M. K. (2003). Families that work: Policies for reconciling parenthood and employment. New York: Russell Sage Foundation.

Karu, M., \& Tremblay, D.-G. (2018). Fathers on parental leave: an analysis of rights and take-up in 29 countries. Community, Work \& Family, 21(3), 344-362.

Knezevic, A. (2008). Overlapping Confidence Intervals and Statistical Significance. StatNews, 73.

Moss, P., \& Deven, F. (2015). Leave policies in challenging times: Reviewing the decade 2004-2014. Community, Work \& Family, 18(2), 137-144.

Multilinks. (2011). Multilinks Database on Intergenerational Policy Indicators. Retrieved 02 July 2019, from http://multilinks-database.wzb.eu

Nieuwenhuis, R., Need, A., \& Van der Kolk, H. (2012). Institutional and demographic explanations of women's employment in 18 OECD countries, 1975-1999. Journal of Marriage and Family, 74(3), 614-630.

Nieuwenhuis, R., Need, A., \& Van der Kolk, H. (2017). Is there such a thing as too long childcare leave? International Journal of Sociology and Social Policy, 37(1/2), 2-15.

OECD. (2005). Society at a glance 2005: OECD social indicators 2005 edition. Paris: OECD publishing.

OECD. (2011). Doing better for families. Paris: OECD Publishing.

OECD. (2018). Education at a Glance 2018: OECD indicators. Paris: OECD Publishing. 
OECD. (2019a). Benefits and wages: Net childcare cost for parents using childcare. Retrieved 02 July 2019, from https://doi.org/10.1787/b0781729-en

OECD. (2019b). Education at a Glance 2019: OECD Indicators. Paris: OECD Publishing.

OECD. (2019c). Unemployment rate (indicator). Retrieved 02 July 2019, from https://data.oecd.org/unemp/unemployment-rate.htm

Olivetti, C., \& Petrongolo, B. (2017). The economic consequences of family policies: lessons from a century of legislation in high-income countries. Journal of Economic Perspectives, 31(1), 205230.

Pettit, B., \& Hook, J. (2005). The structure of women's employment in comparative perspective. Social Forces, 84(2), 779-801.

Snijders, T. A. B., \& Bosker, R. J. (2012). Multilevel analysis: An introduction to basic and advanced multilevel modeling (2nd ed.). London: Sage.

Thévenon, O. (2011). Family policies in OECD countries: A comparative analysis. Population and development review, 37(1), 57-87.

Thévenon, O., \& Luci, A. (2012). Reconciling work, family and child outcomes: What implications for family support policies? Population Research and Policy Review, 31(6), 855-882.

Thévenon, O., \& Solaz, A. (2014). Parental leave and labour market outcomes: Lessons from 40 years of policies in OECD countries. OECD Social, Employment and Migration Working Papers, No. 141.

van Belle, J. (2016). Paternity and parental leave policies across the European Union. Cambridge: RAND Europe.

Van der Lippe, T., \& Van Dijk, L. (2002). Comparative research on women's employment. Annual review of sociology, 28(1), 221-241.

Yerkes, M. A., \& Javornik, J. (2018). Creating capabilities: Childcare policies in comparative perspective. Journal of European social policy, 29(4), 529-544. 
Appendix A

Table A1. Frequency of EETs and NEETs per country (Figure 1)

\begin{tabular}{|c|c|c|c|c|}
\hline \multirow{3}{*}{$\begin{array}{l} \\
\text { Austria }\end{array}$} & \multirow{3}{*}{$\mathrm{N}$} & \multicolumn{3}{|c|}{ Mother-sample } \\
\hline & & EET & NEET & Total \\
\hline & & 267 & 240 & 507 \\
\hline & $\%$ & 52.66 & 47.34 & 100 \\
\hline \multirow[t]{2}{*}{ Belgium } & $\mathrm{N}$ & 218 & 50 & 268 \\
\hline & $\%$ & 81.34 & 18.66 & 100 \\
\hline \multirow[t]{2}{*}{ Bulgaria } & $\mathrm{N}$ & 177 & 228 & 405 \\
\hline & $\%$ & 43.7 & 56.3 & 100 \\
\hline \multirow[t]{2}{*}{ Cyprus } & $\mathrm{N}$ & 121 & 64 & 185 \\
\hline & $\%$ & 65.41 & 34.59 & 100 \\
\hline \multirow[t]{2}{*}{ Czech Republic } & $\mathrm{N}$ & 424 & 251 & 675 \\
\hline & $\%$ & 62.81 & 37.19 & 100 \\
\hline \multirow{2}{*}{ Denmark } & $\mathrm{N}$ & 139 & 32 & 171 \\
\hline & $\%$ & 81.29 & 18.71 & 100 \\
\hline \multirow[t]{2}{*}{ Estonia } & $\mathrm{N}$ & 150 & 60 & 210 \\
\hline & $\%$ & 71.43 & 28.57 & 100 \\
\hline \multirow[t]{2}{*}{ Finland } & $\mathrm{N}$ & 316 & 73 & 389 \\
\hline & $\%$ & 81.23 & 18.77 & 100 \\
\hline \multirow[t]{2}{*}{ France } & $\mathrm{N}$ & 334 & 250 & 584 \\
\hline & $\%$ & 57.19 & 42.81 & 100 \\
\hline \multirow[t]{2}{*}{ Germany } & $\mathrm{N}$ & 188 & 49 & 237 \\
\hline & $\%$ & 79.32 & 20.68 & 100 \\
\hline \multirow[t]{2}{*}{ Greece } & $\mathrm{N}$ & 285 & 473 & 758 \\
\hline & $\%$ & 37.6 & 62.4 & 100 \\
\hline \multirow[t]{2}{*}{ Hungary } & $\mathrm{N}$ & 706 & 196 & 902 \\
\hline & $\%$ & 78.27 & 21.73 & 100 \\
\hline \multirow[t]{2}{*}{ Iceland } & $\mathrm{N}$ & 72 & 31 & 103 \\
\hline & $\%$ & 69.9 & 30.1 & 100 \\
\hline \multirow[t]{2}{*}{ Italy } & $\mathrm{N}$ & 375 & 778 & 1,153 \\
\hline & $\%$ & 32.52 & 67.48 & 100 \\
\hline \multirow[t]{2}{*}{ Latvia } & $\mathrm{N}$ & 104 & 86 & 190 \\
\hline & $\%$ & 54.74 & 45.26 & 100 \\
\hline Lithuania & $\mathrm{N}$ & 215 & 88 & 303 \\
\hline & $\%$ & 70.96 & 29.04 & 100 \\
\hline Luxembourg & $\mathrm{N}$ & 78 & 49 & 127 \\
\hline & $\%$ & 61.42 & 38.58 & 100 \\
\hline Netherlands & $\mathrm{N}$ & 397 & 222 & 619 \\
\hline & $\%$ & 64.14 & 35.86 & 100 \\
\hline Norway & $\mathrm{N}$ & 309 & 18 & 327 \\
\hline & $\%$ & 94.5 & 5.5 & 100 \\
\hline Poland & $\mathrm{N}$ & 1,117 & 641 & 1,758 \\
\hline & $\%$ & 63.54 & 36.46 & 100 \\
\hline Portugal & $\mathrm{N}$ & 254 & 105 & 359 \\
\hline & $\%$ & 70.75 & 29.25 & 100 \\
\hline Romania & $\mathrm{N}$ & 358 & 307 & 665 \\
\hline & $\%$ & 53.83 & 46.17 & 100 \\
\hline Slovak Republic & $\mathrm{N}$ & 182 & 24 & 206 \\
\hline & $\%$ & 88.35 & 11.65 & 100 \\
\hline Slovenia & $\mathrm{N}$ & 118 & 42 & 160 \\
\hline & $\%$ & 73.75 & 26.25 & 100 \\
\hline Spain & $\mathrm{N}$ & 394 & 216 & 610 \\
\hline & $\%$ & 64.59 & 35.41 & 100 \\
\hline Sweden & $\mathrm{N}$ & 543 & 179 & 722 \\
\hline
\end{tabular}




\begin{tabular}{lrrrr} 
& $\%$ & 75.21 & 24.79 & 100 \\
United Kingdom & $\mathrm{N}$ & 727 & 293 & 1,020 \\
& $\%$ & 71.27 & 28.73 & 100 \\
\hline Total & $\mathrm{N}$ & 8,568 & 5,045 & 13,613 \\
& $\%$ & 62.94 & 37.06 & 100 \\
\hline
\end{tabular}

Table A2. Contextual characteristics per country

\begin{tabular}{|c|c|c|c|c|}
\hline & $\begin{array}{l}\text { Guaranteed } \\
\text { childcare placement }\end{array}$ & Childcare costs & $\begin{array}{l}\text { Paid parental leave } \\
\text { duration }\end{array}$ & $\begin{array}{l}\text { Unemployment } \\
\text { rate }\end{array}$ \\
\hline Austria & 0,0 & 9,0 & 9,8 & 4,8 \\
\hline Belgium & 1,0 & 5,0 & 4,6 & 8,3 \\
\hline Bulgaria & 0,0 & 9,0 & 16,8 & 10,3 \\
\hline Cyprus & 0,0 & & 3,1 & 6,3 \\
\hline Czech Republic & 0,0 & $-9,0$ & 17,9 & 7,3 \\
\hline Denmark & 1,0 & 5,0 & 11,7 & 7,0 \\
\hline Estonia & 1,0 & 4,0 & 17,6 & 16,7 \\
\hline Finland & 1,0 & 23,0 & 10,9 & 8,4 \\
\hline France & 0,0 & 4,0 & 13,0 & 9,3 \\
\hline Germany & 1,0 & 5,0 & 12,6 & 7,5 \\
\hline Greece & 0,0 & 5,0 & 4,1 & 12,7 \\
\hline Hungary & 0,0 & 8,0 & 20,5 & 11,2 \\
\hline Iceland & & 6 & & 7,6 \\
\hline Italy & 0,0 & 0,0 & 5,5 & 8,4 \\
\hline Latvia & 0,0 & 13,0 & 12,1 & 19,5 \\
\hline Lithuania & 0,0 & 7,0 & 24,3 & 17,8 \\
\hline Luxembourg & 0,0 & 4,0 & 10,6 & 4,6 \\
\hline Netherlands & 0,0 & 5,0 & 7,0 & 5,0 \\
\hline Norway & 0,0 & 16,0 & 13,7 & 3,7 \\
\hline Poland & 0,0 & 27,0 & 4,1 & 9,7 \\
\hline Portugal & 0,0 & 2,0 & 5,2 & 12,0 \\
\hline Romania & 0,0 & 0,0 & 23,5 & 7,0 \\
\hline Slovak Republic & 0,0 & 32,0 & 11,9 & 14,5 \\
\hline Slovenia & 0,0 & 11,0 & 11,9 & 7,3 \\
\hline Spain & 0,0 & 12,0 & 3,7 & 19,9 \\
\hline Sweden & 1,0 & 5,0 & 9,6 & 8,6 \\
\hline United Kingdom & 0,0 & 4,0 & 3,7 & 7,8 \\
\hline $\mathrm{N}$ country & 26 & 26 & 26 & 27 \\
\hline
\end{tabular}


Table A3. OLS estimates of the relation between motherhood \& NEET (Figure 2)

\begin{tabular}{|c|c|c|c|c|c|}
\hline Country & Coef. & & & 95\% Conf & \\
\hline Hungary & -0.0046 & & 0.0156 & -0.0351 & 0.0260 \\
\hline Norway & 0.0598 & $* *$ & 0.0175 & 0.0254 & 0.0942 \\
\hline Finland & 0.0603 & $* *$ & 0.0198 & 0.0215 & 0.0991 \\
\hline Slovenia & 0.0938 & $* *$ & 0.0289 & 0.0371 & 0.1505 \\
\hline Lithuania & 0.0994 & $* *$ & 0.0293 & 0.0418 & 0.1570 \\
\hline Latvia & 0.1002 & $*$ & 0.0459 & 0.0101 & 0.1903 \\
\hline Denmark & 0.1041 & $* * *$ & 0.0265 & 0.0521 & 0.1562 \\
\hline Estonia & 0.1085 & $* *$ & 0.0339 & 0.0419 & 0.1752 \\
\hline Sweden & 0.1174 & $* * *$ & 0.0156 & 0.0868 & 0.1480 \\
\hline Belgium & 0.1516 & $* * *$ & 0.0231 & 0.1063 & 0.1968 \\
\hline Portugal & 0.1555 & $* * *$ & 0.0228 & 0.1108 & 0.2003 \\
\hline Iceland & 0.1682 & $* * *$ & 0.0468 & 0.0761 & 0.2602 \\
\hline Romania & 0.1941 & $* * *$ & 0.0189 & 0.1571 & 0.2311 \\
\hline Cyprus & 0.1993 & $* * *$ & 0.0348 & 0.1310 & 0.2675 \\
\hline France & 0.2091 & $* * *$ & 0.0197 & 0.1705 & 0.2478 \\
\hline Spain & 0.2212 & $* * *$ & 0.0173 & 0.1873 & 0.2550 \\
\hline Czech Republic & 0.2382 & $* * *$ & 0.0174 & 0.2042 & 0.2723 \\
\hline Netherlands & 0.2538 & $* * *$ & 0.0151 & 0.2242 & 0.2834 \\
\hline Luxembourg & 0.2625 & $* * *$ & 0.0328 & 0.1981 & 0.3269 \\
\hline United Kingdom & 0.2636 & $* * *$ & 0.0121 & 0.2398 & 0.2874 \\
\hline Bulgaria & 0.2644 & $* * *$ & 0.0248 & 0.2159 & 0.3130 \\
\hline Greece & 0.2812 & $* * *$ & 0.0203 & 0.2415 & 0.3209 \\
\hline Poland & 0.2839 & $* * *$ & 0.0118 & 0.2607 & 0.3070 \\
\hline Italy & 0.3067 & $* * *$ & 0.0152 & 0.2770 & 0.3364 \\
\hline Austria & 0.3165 & $* * *$ & 0.0189 & 0.2795 & 0.3535 \\
\hline Slovak Republic & 0.3365 & $* * *$ & 0.0243 & 0.2888 & 0.3843 \\
\hline Germany & 0.3383 & $* * *$ & 0.0192 & 0.3006 & 0.3759 \\
\hline
\end{tabular}

$* p<0.05$, ** $p<0.01$, *** $p<0.001$; Standard errors in parentheses; Models are based on women aged 20-29; Models are controlled for age, education level and migration background 
Table A4. Multilevel logistic regression: estimates of the relation between family policies and use of parental leaveyoung mothers aged 15-29 (logits)

\begin{tabular}{|c|c|c|c|}
\hline & M0 & M1 & M2 \\
\hline Paid parental leave duration & & $\begin{array}{l}0.958 * * \\
(0.338)\end{array}$ & $\begin{array}{l}0.925 * * \\
(0.335)\end{array}$ \\
\hline \multicolumn{4}{|l|}{ Control variables: } \\
\hline Use of ECEC ( $\mathrm{No}=$ ref.) & & & $\begin{array}{l}0.146^{* *} \\
(0.050)\end{array}$ \\
\hline \multicolumn{4}{|l|}{ Education level (Low=ref.) } \\
\hline Medium & & & $\begin{array}{l}0.664 * * * \\
(0.059)\end{array}$ \\
\hline High & & & $\begin{array}{l}0.574 * * * \\
(0.074)\end{array}$ \\
\hline \multicolumn{4}{|l|}{ Age (Age 15-19=ref.) } \\
\hline Age $20-24$ & & & $\begin{array}{l}0.966 * * * \\
(0.175)\end{array}$ \\
\hline Age $25-29$ & & & $\begin{array}{l}1.358 * * * \\
(0.174)\end{array}$ \\
\hline \multicolumn{4}{|l|}{ Migration background (Native=ref.) } \\
\hline Foreigner from Europe & & & $\begin{array}{l}-0.576^{* * *} \\
(0.097)\end{array}$ \\
\hline Foreigner from outside Europe & & & $\begin{array}{l}-0.577 * * * \\
(0.129)\end{array}$ \\
\hline Unemployment rate & & & $\begin{array}{l}0.210 \\
(0.295)\end{array}$ \\
\hline Constant & $\begin{array}{l}-0.706 \sim \\
(0.371)\end{array}$ & $\begin{array}{l}-0.948 * * \\
(0.337) \\
\end{array}$ & $\begin{array}{l}-2.631 * * * \\
(0.371)\end{array}$ \\
\hline Country variance & $\begin{array}{l}3.569 * * * \\
(1.055)\end{array}$ & $\begin{array}{l}2.714 * * * \\
(0.804)\end{array}$ & $\begin{array}{l}\text { 2.619*** } \\
(0.776)\end{array}$ \\
\hline $\mathrm{N}$ country & 26 & 26 & 26 \\
\hline $\mathrm{N}$ individual & 13,822 & 13,822 & 13,822 \\
\hline
\end{tabular}

$\sim p<0.10, * p<0.05, * * p<0.01, * * * p<0.001$; Standard errors in parentheses; Iceland is excluded from analyses because of missing data on paid parental leave duration 
Table A5. Multilevel logistic regression: estimates of the relation between parental leave use and NEET risks later in life - young mothers aged 15-29 (logits)

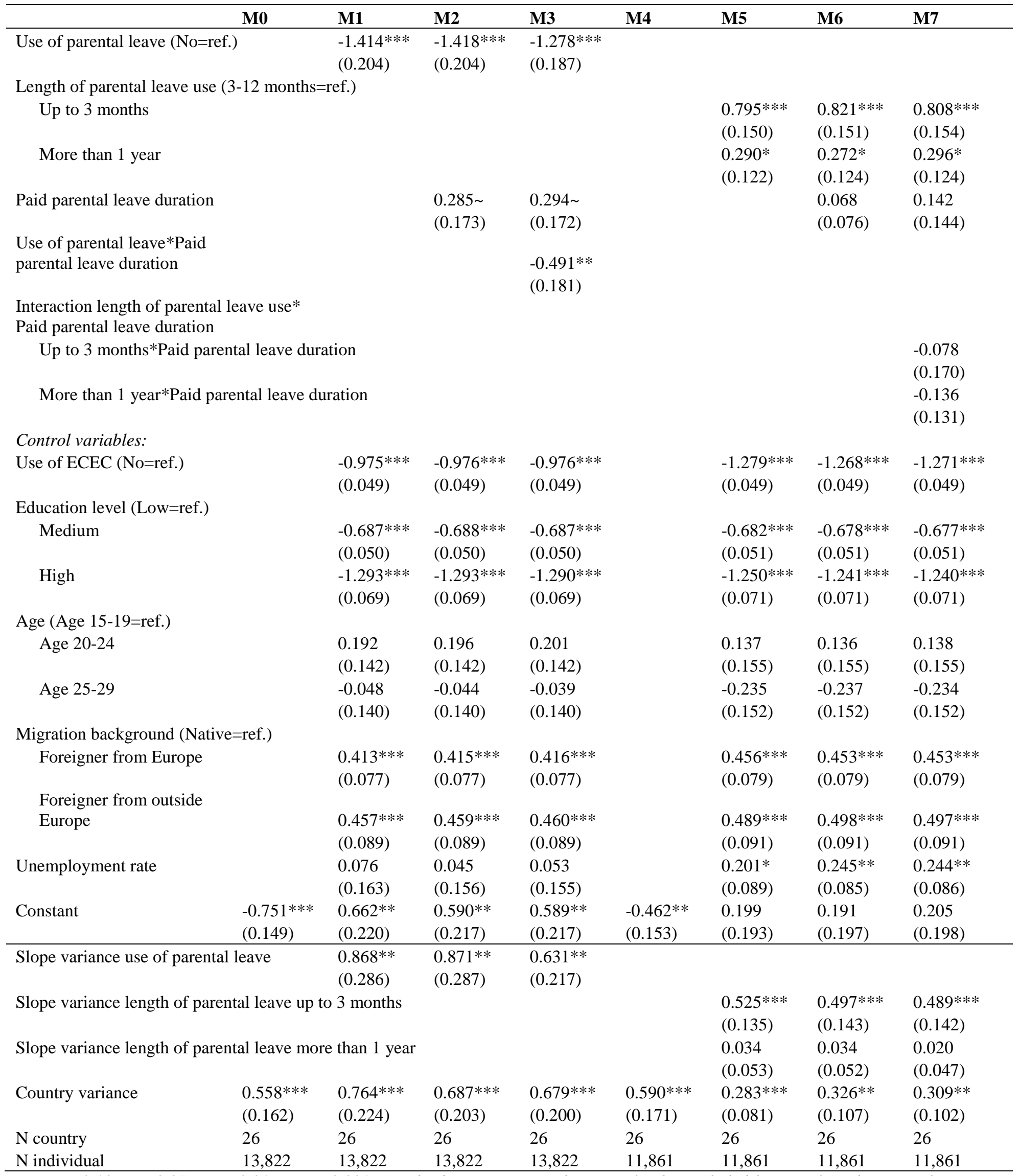
$\sim p<0.10, * p<0.05, * * p<0.01, * * * p<0.001$; Standard errors in parentheses; Iceland is excluded from analyses because of missing data on paid parental leave duration; the number of individuals is lower in Models 4-7 because we left out mothers who are still on parental leave 
Table A6. Multilevel logistic regression: estimates of the relation between family policies and use of ECEC-young mothers aged 15-29 (logits)

\begin{tabular}{llll}
\hline & M0 & M1 & M2 \\
\hline Guaranteed childcare placement (No=ref.) & & $0.844 * *$ & $0.772 * *$ \\
& & $(0.260)$ & $(0.255)$
\end{tabular}

Childcare costs

M3 M4

Control variables:

Use of parental leave (No=ref.)

$\begin{array}{ll}0.144 * * & 0.149 * * \\ (0.049) & (0.049) \\ & \\ 0.155^{* *} & 0.140 * * \\ (0.049) & (0.049) \\ 0.132 * & 0.120 \sim \\ (0.061) & (0.062)\end{array}$

Age (Age 15-19=ref.)

Age 20-24

$0.901 * * *$

$0.901 * * *$

$(0.191)$

$(0.191)$

Age 25-29

$1.416 * * *$

$1.425 * * *$

$(0.188)$

(0.189)

Migration background (Native=ref.)

Foreigner from Europe

$-0.036$

$-0.051$

(0.074)

(0.075)

Foreigner from outside Europe

$-0.123$

$-0.149 \sim$

(0.085)

(0.087)

$-0.155$

$-0.195$

(0.099)

(0.122)

Constant

$-0.614 * * * \quad-0.809 * * *$

$-2.233 * * *$

$-0.585 * * *$

$-0.586 * * *$

$-2.017 * * *$

(0.129)

(0.125)

(0.221)

(0.134)

(0.133)

$(0.225)$

Country variance

(0.121)

$0.297 * * *$

$0.284 * * *$

$0.449 * * *$

$0.449 * * *$

$0.414 * * *$

N country

26

(0.086)

(0.083)

13,822

26

26

(0.129)

(0.129)

(0.120)

$\mathrm{N}$ individual

13,822

13,822

$26 \quad 26$

26

$\sim p<0.10, * p<0.05, * * p<0.01, * * * p<0.001 ;$ Standard errors in parentheses; Iceland is excluded from Models 0-2, and Cyprus is excluded from Models 3-5 because of missing data on the related family policy 
Table A7. Multilevel logistic regression: estimates of the relation between childcare use and NEET risks later in lifeyoung mothers aged 15-29 (logits)

\begin{tabular}{l} 
M0 \\
\hline Use of ECEC (No=ref.) \\
$\begin{array}{l}\text { Guaranteed childcare placement } \\
\text { (No=ref.) }\end{array}$ \\
Use of ECEC*Guaranteed childcare \\
placement
\end{tabular}

Childcare costs

Use of ECEC*Childcare

costs

\begin{tabular}{lll} 
M1 & M2 & M3 \\
\hline$-0.960 * * *$ & $-0.959 * * *$ & $-0.978 * * *$ \\
$(0.122)$ & $(0.122)$ & $(0.138)$ \\
& & \\
& -0.143 & -0.151 \\
& $(0.343)$ & $(0.345)$ \\
& & 0.085 \\
& & $(0.295)$
\end{tabular}

Control variables:

Use of parental leave

(No=ref.)

Education level

(Low=ref.)

Medium

High

Age (Age 15-19=ref.)

Age 20-24

Age 25-29

Migration background

(Native=ref.)

Foreigner from

Europe

Foreigner from

outside Europe

Unemployment rate

Constant

$-0.751 * * *$

$-0.669 * * *$
$(0.049)$
$-1.240 * * *$
$(0.069)$

$-0.668 * * *$

(0.049)

$-0.668 * * *$

$-1.240 * * *$

$(0.049)$

$\begin{array}{lll}-1.645 * * * & -1.644 * * * & -1.644 * * * \\ (0.056) & (0.056) & (0.056)\end{array}$

(0.069)

$-1.240 * * *$

(0.069)

$\begin{array}{lll}0.127 & 0.127 & 0.127 \\ (0.139) & (0.139) & (0.139) \\ -0.117 & -0.118 & -0.118 \\ (0.137) & (0.137) & (0.137)\end{array}$

$0.424 * * *$

$0.424 * * *$

$0.424 * * *$

(0.076)

(0.076)

(0.076)

$0.446 * * *$

$0.446 * * *$

$0.446 * * *$

(0.090)

(0.090)

(0.090)

0.133

0.130

0.130

(0.132)

$(0.132)$

(0.132)

$0.721 * * *$

$0.753 * * *$

$0.754 * * *$

(0.208)

(0.208)

(0.194)

Slope variance use of ECEC

(0.149)

$0.297 * *$

$0.298 * * \quad 0.297 * *$

(0.105)

(0.105)

(0.105)

Country variance

$0.558 * * *$

$0.510 * * *$

$0.506 * * *$

$0.506 * * *$

(0.151)

$(0.152)$

N country

26

26

13,822

13,822

26

13,822

13,822

individual

$\sim p<0.10, * p<0.05, * * p<0.01, * * * p<0.001 ;$ Standard errors in par

from Model 4-7 because of missing data on the related family policy
$-0.758 * * *$

M5

$-0.964 * * *$

M6

M7

(0.123)

$-0.963 * * *$

$-0.963 * * *$

(0.123)

$-0.180 \quad-0.181$

$(0.156) \quad(0.157)$

0.015

(0.136)

$\begin{array}{lll}-1.644 * * * & -1.642 * * * & -1.642 * * * \\ (0.056) & (0.056) & (0.056)\end{array}$

$-0.677 * * * \quad-0.676 * * * \quad-0.676 * * *$

$\begin{array}{lll}(0.049) & (0.049) & (0.049)\end{array}$

$-1.255^{* * *} \quad-1.253 * * * \quad-1.253 * * *$

$\begin{array}{lll}(0.069) & (0.069) & (0.069)\end{array}$

$\begin{array}{lll}0.120 & 0.120 & 0.120 \\ (0.139) & (0.139) & (0.139) \\ -0.119 & -0.120 & -0.120 \\ (0.138) & (0.138) & (0.138)\end{array}$

0.120

(0.139)

$-0.120$

(0.138)

(0.138)

(0.138)

\section{$0.409 * * * \quad 0.409 * * * \quad 0.409 * * *$}

$\begin{array}{lll}(0.077) & (0.077) \quad(0.077)\end{array}$

$0.438 * * * \quad 0.437 * * * \quad 0.437 * * *$

$\begin{array}{lll}(0.091) & (0.091) & (0.091)\end{array}$

$\begin{array}{lll}0.131 & 0.164 & 0.164\end{array}$

$\begin{array}{lll}(0.134) & (0.134) \quad(0.134)\end{array}$

$0.731 * * * \quad 0.729 * * * \quad 0.729 * * *$

$\begin{array}{lll}(0.194) & (0.192) & (0.192)\end{array}$

$0.303 * * \quad 0.303 * * \quad 0.303 * *$

$\begin{array}{lll}(0.107) & (0.107) \quad(0.107)\end{array}$

$\begin{array}{llll}0.558 * * * & 0.513 * * * & 0.487 * * * & 0.488 * * * \\ (0.162) & (0.153) & (0.146) & (0.146)\end{array}$

$\begin{array}{llll}26 & 26 & 26 & 26\end{array}$

$13,738 \quad 13,738 \quad 13,738 \quad 13,738$

13,738 
Table A8. Multilevel logistic regression: estimates of the relation between family policies and use of parental leavewithout Iceland and Cyprus (logits)

\begin{tabular}{|c|c|c|c|}
\hline & M0 & M1 & M2 \\
\hline Paid parental leave duration & & $\begin{array}{l}0.786^{*} \\
(0.320)\end{array}$ & $\begin{array}{l}0.747^{*} \\
(0.315)\end{array}$ \\
\hline \multicolumn{4}{|l|}{ Control variables: } \\
\hline Use of ECEC ( $\mathrm{No}=$ ref.) & & & $\begin{array}{l}0.151 * * \\
(0.050)\end{array}$ \\
\hline \multicolumn{4}{|l|}{ Education level (Low=ref.) } \\
\hline Medium & & & $\begin{array}{l}0.663 * * * \\
(0.059)\end{array}$ \\
\hline High & & & $\begin{array}{l}0.574 * * * \\
(0.074)\end{array}$ \\
\hline \multicolumn{4}{|l|}{ Age (Age 15-19=ref.) } \\
\hline Age $20-24$ & & & $\begin{array}{l}0.393 * * * \\
(0.055)\end{array}$ \\
\hline \multicolumn{4}{|l|}{ Migration background (Native=ref.) } \\
\hline Foreigner from Europe & & & $\begin{array}{l}-0.569 * * * \\
(0.098)\end{array}$ \\
\hline Foreigner from outside Europe & & & $\begin{array}{l}-0.566^{* * * *} \\
(0.129)\end{array}$ \\
\hline Unemployment rate & & & $\begin{array}{l}0.135 \\
(0.276)\end{array}$ \\
\hline Constant & $\begin{array}{l}-0.477 \\
(0.339) \\
\end{array}$ & $\begin{array}{l}-0.730 * \\
(0.322) \\
\end{array}$ & $\begin{array}{l}-1.482 * * * \\
(0.320)\end{array}$ \\
\hline Country variance & $\begin{array}{l}2.862 * * * \\
(0.819)\end{array}$ & $\begin{array}{l}2.301 * * * \\
(0.660)\end{array}$ & $\begin{array}{l}2.204 * * * \\
(0.633)\end{array}$ \\
\hline $\mathrm{N}$ country & 25 & 25 & 25 \\
\hline $\mathrm{N}$ individual & 13,325 & 13,325 & 13,325 \\
\hline
\end{tabular}

$\sim p<0.10, * p<0.05, * * p<0.01, * * * p<0.001 ;$ Standard errors in parentheses; Iceland and Cyprus are excluded from analyses 
Table A9. Multilevel logistic regression: estimates of the relation between parental leave use and NEET risks later in life - without Iceland and Cyprus (logits)

\begin{tabular}{|c|c|c|c|c|c|c|c|c|}
\hline & M0 & M1 & M2 & M3 & M4 & M5 & M6 & M7 \\
\hline Use of parental leave $(\mathrm{No}=\mathrm{ref}$. & & $\begin{array}{l}-1.412 * * * \\
(0.204)\end{array}$ & $\begin{array}{l}-1.415^{* * *} \\
(0.204)\end{array}$ & $\begin{array}{l}-1.263 * * * \\
(0.187)\end{array}$ & & & & \\
\hline \multicolumn{9}{|l|}{$\begin{array}{l}\text { Length of parental leave use } \\
(3-12 \text { months=ref.) }\end{array}$} \\
\hline Up to 3 months & & & & & & $\begin{array}{l}0.803 * * * \\
(0.149)\end{array}$ & $\begin{array}{l}0.829 * * * \\
(0.148)\end{array}$ & $\begin{array}{l}0.837 * * * \\
(0.151)\end{array}$ \\
\hline More than 1 year & & & & & & $\begin{array}{l}0.282 * \\
(0.125)\end{array}$ & $\begin{array}{l}0.261 * \\
(0.129)\end{array}$ & $\begin{array}{l}0.291 * \\
(0.130)\end{array}$ \\
\hline Paid parental leave duration & & & $\begin{array}{l}0.302 \sim \\
(0.179)\end{array}$ & $\begin{array}{l}0.313 \sim \\
(0.178)\end{array}$ & & & $\begin{array}{l}0.081 \\
(0.080)\end{array}$ & $\begin{array}{l}0.134 \\
(0.150)\end{array}$ \\
\hline $\begin{array}{l}\text { Use of parental leave*Paid } \\
\text { parental leave duration }\end{array}$ & & & & $\begin{array}{l}-0.503 * * \\
(0.179)\end{array}$ & & & & \\
\hline $\begin{array}{l}\text { Interaction length of parental le } \\
\text { *Paid parental leave duration } \\
\text { Up to } 3 \text { months*Paid paren } \\
\text { leave duration }\end{array}$ & $\begin{array}{l}\text { ave use } \\
\text { al }\end{array}$ & & & & & & & $\begin{array}{l}0.036 \\
(0.166)\end{array}$ \\
\hline $\begin{array}{l}\text { More than } 1 \text { year*Paid pare } \\
\text { leave duration }\end{array}$ & tal & & & & & & & $\begin{array}{l}-0.121 \\
(0.136)\end{array}$ \\
\hline \multicolumn{9}{|l|}{ Control variables: } \\
\hline Use of ECEC (No=ref.) & & $\begin{array}{l}-0.960 * * * \\
(0.049)\end{array}$ & $\begin{array}{l}-0.961 * * * \\
(0.049)\end{array}$ & $\begin{array}{l}-0.961 * * * \\
(0.049)\end{array}$ & & $\begin{array}{l}-1.271 * * * \\
(0.050)\end{array}$ & $\begin{array}{l}-1.262 * * * \\
(0.050)\end{array}$ & $\begin{array}{l}-1.271 * * * \\
(0.050)\end{array}$ \\
\hline \multicolumn{9}{|l|}{ Education level (Low=ref.) } \\
\hline Medium & & $\begin{array}{l}-0.710 * * * \\
(0.050)\end{array}$ & $\begin{array}{l}-0.711 * * * \\
(0.050)\end{array}$ & $\begin{array}{l}-0.710 * * * \\
(0.050)\end{array}$ & & $\begin{array}{l}-0.706 * * * \\
(0.052)\end{array}$ & $\begin{array}{l}-0.701 * * * \\
(0.052)\end{array}$ & $\begin{array}{l}-0.700 * * * \\
(0.052)\end{array}$ \\
\hline High & & $\begin{array}{l}-1.318 * * * \\
(0.070)\end{array}$ & $\begin{array}{l}-1.319 * * * \\
(0.070)\end{array}$ & $\begin{array}{l}-1.316^{* * * *} \\
(0.070)\end{array}$ & & $\begin{array}{l}-1.276^{* * * *} \\
(0.072)\end{array}$ & $\begin{array}{l}-1.267 * * * \\
(0.072)\end{array}$ & $\begin{array}{l}-1.267 * * * \\
(0.072)\end{array}$ \\
\hline \multicolumn{9}{|l|}{ Age (Age 15-19=ref.) } \\
\hline Age $20-24$ & & $\begin{array}{l}-0.244 * * * \\
(0.049)\end{array}$ & $\begin{array}{l}-0.243^{* * *} \\
(0.049)\end{array}$ & $\begin{array}{l}-0.243 * * * \\
(0.049)\end{array}$ & & $\begin{array}{l}-0.377 * * * \\
(0.052)\end{array}$ & $\begin{array}{l}-0.378 * * * \\
(0.052)\end{array}$ & $\begin{array}{l}-0.379 * * * \\
(0.052)\end{array}$ \\
\hline \multicolumn{9}{|c|}{ Migration background (Native=ref.) } \\
\hline Foreigner from Europe & & $\begin{array}{l}0.376 * * * \\
(0.079)\end{array}$ & $\begin{array}{l}0.378 * * * \\
(0.079)\end{array}$ & $\begin{array}{l}0.380 * * * \\
(0.079)\end{array}$ & & $\begin{array}{l}0.421 * * * \\
(0.081)\end{array}$ & $\begin{array}{l}0.418 * * * \\
(0.081)\end{array}$ & $\begin{array}{l}0.414 * * * \\
(0.081)\end{array}$ \\
\hline $\begin{array}{l}\text { Foreigner from outside } \\
\text { Europe }\end{array}$ & & $\begin{array}{l}0.462 * * * \\
(0.092)\end{array}$ & $\begin{array}{l}0.465 * * * \\
(0.092)\end{array}$ & $\begin{array}{l}0.465 * * * \\
(0.092)\end{array}$ & & $\begin{array}{l}0.495 * * * \\
(0.094)\end{array}$ & $\begin{array}{l}0.504 * * * \\
(0.093)\end{array}$ & $\begin{array}{l}0.493 * * * \\
(0.094)\end{array}$ \\
\hline Unemployment rate & & $\begin{array}{l}0.073 \\
(0.169)\end{array}$ & $\begin{array}{l}0.052 \\
(0.160)\end{array}$ & $\begin{array}{l}0.061 \\
(0.159)\end{array}$ & & $\begin{array}{l}0.201 * \\
(0.089)\end{array}$ & $\begin{array}{l}0.257 * * \\
(0.084)\end{array}$ & $\begin{array}{l}0.257 * * \\
(0.082)\end{array}$ \\
\hline Constant & $\begin{array}{l}-0.776^{* * * *} \\
(0.152) \\
\end{array}$ & $\begin{array}{l}0.894 * * * \\
(0.188) \\
\end{array}$ & $\begin{array}{l}0.801 * * * \\
(0.188)\end{array}$ & $\begin{array}{l}0.805 * * * \\
(0.186) \\
\end{array}$ & $\begin{array}{l}-0.475 * * \\
(0.156) \\
\end{array}$ & $\begin{array}{l}0.358 * * \\
(0.134) \\
\end{array}$ & $\begin{array}{l}0.344^{*} \\
(0.142) \\
\end{array}$ & $\begin{array}{l}0.378 * \\
(0.148) \\
\end{array}$ \\
\hline Slope variance use of parental & eave & $\begin{array}{l}0.862 * * \\
(0.284)\end{array}$ & $\begin{array}{l}0.866 * * \\
(0.285)\end{array}$ & $\begin{array}{l}0.617 * * \\
(0.212)\end{array}$ & & & & \\
\hline $\begin{array}{l}\text { Slope variance length of parent } \\
\text { leave up to } 3 \text { months }\end{array}$ & & & & & & $\begin{array}{l}0.517 * * * \\
(0.135)\end{array}$ & $\begin{array}{l}0.476 * * * \\
(0.141)\end{array}$ & $\begin{array}{l}0.447 * * * \\
(0.133)\end{array}$ \\
\hline $\begin{array}{l}\text { Slope variance length of parent } \\
\text { leave more than } 1 \text { year }\end{array}$ & & & & & & $\begin{array}{l}0.041 \\
(0.058)\end{array}$ & $\begin{array}{l}0.044 \\
(0.059)\end{array}$ & $\begin{array}{l}0.033 \\
(0.054)\end{array}$ \\
\hline Country variance & $\begin{array}{l}0.561 * * * \\
(0.166)\end{array}$ & $\begin{array}{l}0.781 * * * \\
(0.234)\end{array}$ & $\begin{array}{l}0.697 * * * \\
(0.210)\end{array}$ & $\begin{array}{l}0.689 * * * \\
(0.207)\end{array}$ & $\begin{array}{l}0.589 * * * \\
(0.175)\end{array}$ & $\begin{array}{l}0.291 * * * \\
(0.084)\end{array}$ & $\begin{array}{l}0.348 * * \\
(0.116)\end{array}$ & $\begin{array}{l}0.342 * * \\
(0.116)\end{array}$ \\
\hline $\mathrm{N}$ country & 25 & 25 & 25 & 25 & 25 & 25 & 25 & 25 \\
\hline $\mathrm{N}$ individual & 13,325 & 13,325 & 13,325 & 13,325 & 11,406 & 11,406 & 11,406 & 11,406 \\
\hline
\end{tabular}
$\sim p<0.10, * p<0.05, * * p<0.01, * * * p<0.001 ;$ Standard errors in parentheses; Iceland and Cyprus are excluded from analyses; the number of individuals is lower in Models 4-7 because we left out mothers who are still on parental leave 
Table A10. Multilevel logistic regression: estimates of the relation between family policies and use of ECEC-without Iceland and Cyprus (logits)

\begin{tabular}{|c|c|c|c|c|c|}
\hline & Mo & M1 & M2 & M3 & M4 \\
\hline Guaranteed childcare placement $(\mathrm{No}=\mathrm{ref})$. & & $\begin{array}{l}0.858 * * \\
(0.265)\end{array}$ & $\begin{array}{l}0.785^{* *} \\
(0.260)\end{array}$ & & \\
\hline Childcare costs & & & & $\begin{array}{l}0.034 \\
(0.143)\end{array}$ & $\begin{array}{l}0.042 \\
(0.140)\end{array}$ \\
\hline \multicolumn{6}{|l|}{ Control variables: } \\
\hline Use of parental leave ( $\mathrm{No}=$ ref.) & & & $\begin{array}{l}0.149 * * \\
(0.050)\end{array}$ & & $\begin{array}{l}0.155^{* *} \\
(0.050)\end{array}$ \\
\hline \multicolumn{6}{|l|}{ Education level (Low=ref.) } \\
\hline Medium & & & $\begin{array}{l}0.148^{* *} \\
(0.049)\end{array}$ & & $\begin{array}{l}0.149 * * \\
(0.049)\end{array}$ \\
\hline High & & & $\begin{array}{l}0.125^{*} \\
(0.062)\end{array}$ & & $\begin{array}{l}0.127 * \\
(0.062)\end{array}$ \\
\hline \multicolumn{6}{|l|}{ Age (Age 15-19=ref.) } \\
\hline Age $20-24$ & & & $\begin{array}{l}0.522 * * * \\
(0.050)\end{array}$ & & $\begin{array}{l}0.521 * * * \\
(0.050)\end{array}$ \\
\hline \multicolumn{6}{|l|}{ Migration background (Native $=$ ref.) } \\
\hline Foreigner from Europe & & & $\begin{array}{l}-0.043 \\
(0.076)\end{array}$ & & $\begin{array}{l}-0.042 \\
(0.076)\end{array}$ \\
\hline Foreigner from outside Europe & & & $\begin{array}{l}-0.145 \sim \\
(0.087)\end{array}$ & & $\begin{array}{l}-0.145 \sim \\
(0.087)\end{array}$ \\
\hline Unemployment rate & & & $\begin{array}{l}-0.146 \\
(0.103)\end{array}$ & & $\begin{array}{l}-0.174 \\
(0.122)\end{array}$ \\
\hline Constant & $\begin{array}{l}-0.591 * * * \\
(0.134)\end{array}$ & $\begin{array}{l}-0.796^{* * * *} \\
(0.129)\end{array}$ & $\begin{array}{l}-1.343^{* * *} \\
(0.137)\end{array}$ & $\begin{array}{l}-0.591 * * * \\
(0.134)\end{array}$ & $\begin{array}{l}-1.158^{* * *} \\
(0.139)\end{array}$ \\
\hline Country variance & $\begin{array}{l}0.437 * * * \\
(0.128)\end{array}$ & $\begin{array}{l}0.304 * * * \\
(0.090)\end{array}$ & $\begin{array}{l}0.292 * * * \\
(0.087)\end{array}$ & $\begin{array}{l}0.437 * * * \\
(0.128)\end{array}$ & $\begin{array}{l}0.401 * * * \\
(0.118)\end{array}$ \\
\hline $\mathrm{N}$ country & 25 & 25 & 25 & 25 & 25 \\
\hline $\mathrm{N}$ individual & 13,325 & 13,325 & 13,325 & 13,325 & 13,325 \\
\hline
\end{tabular}

$\sim p<0.10, * p<0.05, * * p<0.01, * * * p<0.001 ;$ Standard errors in parentheses; Iceland and Cyprus are excluded from analyses 
Table A11. Multilevel logistic regression: estimates of the relation between childcare use and NEET risks later in life - without Iceland and Cyprus (logits)

\begin{tabular}{|c|c|c|c|c|c|c|}
\hline \multirow[b]{2}{*}{ Use of ECEC (No=ref.) } & M0 & M1 & M2 & M3 & M4 & M5 \\
\hline & & $\begin{array}{l}-0.937 * * * \\
(0.125)\end{array}$ & $\begin{array}{l}-0.936 * * * \\
(0.125)\end{array}$ & $\begin{array}{l}-0.956 \text { *** } \\
(0.142)\end{array}$ & $\begin{array}{l}-0.936^{* * *} \\
(0.125)\end{array}$ & $\begin{array}{l}-0.936 * * * \\
(0.125)\end{array}$ \\
\hline \multicolumn{2}{|c|}{ Guaranteed childcare placement ( $\mathrm{No}=$ ref.) } & & $\begin{array}{l}-0.169 \\
(0.344)\end{array}$ & $\begin{array}{l}-0.178 \\
(0.346)\end{array}$ & & \\
\hline \multicolumn{2}{|c|}{ Use of ECEC ${ }^{*}$ Guaranteed childcare placement } & & & $\begin{array}{l}0.087 \\
(0.298)\end{array}$ & & \\
\hline \multicolumn{2}{|l|}{ Childcare costs } & & & & $\begin{array}{l}-0.174 \\
(0.156)\end{array}$ & $\begin{array}{l}-0.174 \\
(0.156)\end{array}$ \\
\hline \multicolumn{2}{|l|}{ Use of ECEC $*$ Childcare costs } & & & & & $\begin{array}{l}0.003 \\
(0.136)\end{array}$ \\
\hline \multicolumn{7}{|l|}{ Control variables: } \\
\hline \multicolumn{2}{|l|}{ Use of parental leave (No=ref.) } & $\begin{array}{l}-1.630 * * * \\
(0.056)\end{array}$ & $\begin{array}{l}-1.629 * * * \\
(0.056)\end{array}$ & $\begin{array}{l}-1.629 * * * \\
(0.057)\end{array}$ & $\begin{array}{l}-1.628 * * * \\
(0.056)\end{array}$ & $\begin{array}{l}-1.628 * * * \\
(0.056)\end{array}$ \\
\hline \multicolumn{7}{|l|}{ Education level (Low=ref.) } \\
\hline Medium & & $\begin{array}{l}-0.691 * * * \\
(0.050)\end{array}$ & $\begin{array}{l}-0.690 * * * \\
(0.050)\end{array}$ & $\begin{array}{l}-0.690 * * * \\
(0.050)\end{array}$ & $\begin{array}{l}-0.689 * * * \\
(0.050)\end{array}$ & $\begin{array}{l}-0.689 * * * \\
(0.050)\end{array}$ \\
\hline High & & $\begin{array}{l}-1.264 * * * \\
(0.070)\end{array}$ & $\begin{array}{l}-1.264 * * * \\
(0.070)\end{array}$ & $\begin{array}{l}-1.264 * * * \\
(0.070)\end{array}$ & $\begin{array}{l}-1.263^{* * * *} \\
(0.070)\end{array}$ & $\begin{array}{l}-1.263 * * * \\
(0.070)\end{array}$ \\
\hline \multicolumn{7}{|l|}{ Age (Age 15-19=ref.) } \\
\hline Age 20-24 & & $\begin{array}{l}-0.248 * * * \\
(0.049)\end{array}$ & $\begin{array}{l}-0.248 * * * \\
(0.049)\end{array}$ & $\begin{array}{l}-0.248 * * * \\
(0.049)\end{array}$ & $\begin{array}{l}-0.248 * * * \\
(0.049)\end{array}$ & $\begin{array}{l}-0.248 * * * \\
(0.049)\end{array}$ \\
\hline \multicolumn{7}{|l|}{ Migration background (Native=ref.) } \\
\hline Foreigner from Europe & & $\begin{array}{l}0.389 * * * \\
(0.078)\end{array}$ & $\begin{array}{l}0.389 * * * \\
(0.078)\end{array}$ & $\begin{array}{l}0.389 * * * \\
(0.078)\end{array}$ & $\begin{array}{l}0.388 * * * \\
(0.078)\end{array}$ & $\begin{array}{l}0.388 * * * \\
(0.078)\end{array}$ \\
\hline Foreigner from outside Europe & & $\begin{array}{l}0.448 * * * \\
(0.092)\end{array}$ & $\begin{array}{l}0.448 * * * \\
(0.092)\end{array}$ & $\begin{array}{l}0.448 * * * \\
(0.092)\end{array}$ & $\begin{array}{l}0.447 * * * \\
(0.092)\end{array}$ & $\begin{array}{l}0.447 * * * \\
(0.092)\end{array}$ \\
\hline Unemployment rate & & $\begin{array}{l}0.127 \\
(0.135)\end{array}$ & $\begin{array}{l}0.122 \\
(0.135)\end{array}$ & $\begin{array}{l}0.122 \\
(0.135)\end{array}$ & $\begin{array}{l}0.158 \\
(0.135)\end{array}$ & $\begin{array}{l}0.158 \\
(0.135)\end{array}$ \\
\hline Constant & $\begin{array}{l}-0.776^{* * * *} \\
(0.152)\end{array}$ & $\begin{array}{l}0.879 * * * \\
(0.155)\end{array}$ & $\begin{array}{l}0.918 * * * \\
(0.173)\end{array}$ & $\begin{array}{l}0.919 * * * \\
(0.173)\end{array}$ & $\begin{array}{l}0.879 * * * \\
(0.151)\end{array}$ & $\begin{array}{l}0.879 * * * \\
(0.151)\end{array}$ \\
\hline Slope variance use of ECEC & & $\begin{array}{l}0.300 * * \\
(0.109)\end{array}$ & $\begin{array}{l}0.301 * * \\
(0.109)\end{array}$ & $\begin{array}{l}0.300 * * \\
(0.109)\end{array}$ & $\begin{array}{l}0.300 * * \\
(0.109)\end{array}$ & $\begin{array}{l}0.300 * * \\
(0.109)\end{array}$ \\
\hline Country variance & $\begin{array}{l}0.561 * * * \\
(0.166)\end{array}$ & $\begin{array}{l}0.506 * * \\
(0.154)\end{array}$ & $\begin{array}{l}0.500 * * \\
(0.153)\end{array}$ & $\begin{array}{l}0.501 * * \\
(0.153)\end{array}$ & $\begin{array}{l}0.481 * * \\
(0.147)\end{array}$ & $\begin{array}{l}0.481 * * \\
(0.147)\end{array}$ \\
\hline $\mathrm{N}$ country & 25 & 25 & 25 & 25 & 25 & 25 \\
\hline $\mathrm{N}$ individual & 13,325 & 13,325 & 13,325 & 13,325 & 13,325 & 13,325 \\
\hline
\end{tabular}

$\sim p<0.10, * p<0.05, * * p<0.01$, *** $p<0.001$; Standard errors in parentheses; Iceland and Cyprus are excluded from analyses 
Table A12. Multilevel logistic regression: estimates of the relation between family policies and use of parental leave without controlling for use of ECEC (logits)

\begin{tabular}{|c|c|c|c|}
\hline & M0 & M1 & M2 \\
\hline Paid parental leave duration & & $\begin{array}{l}0.987 * * \\
(0.339)\end{array}$ & $\begin{array}{l}0.931 * * \\
(0.334)\end{array}$ \\
\hline \multicolumn{4}{|l|}{ Control variables: } \\
\hline \multicolumn{4}{|l|}{ Education level (Low=ref.) } \\
\hline Medium & & & $\begin{array}{l}0.666 * * * \\
(0.059)\end{array}$ \\
\hline High & & & $\begin{array}{l}0.577 * * * \\
(0.074)\end{array}$ \\
\hline \multicolumn{4}{|l|}{ Age (Age 15-19=ref.) } \\
\hline Age $20-24$ & & & $\begin{array}{l}0.409 * * * \\
(0.055)\end{array}$ \\
\hline \multicolumn{4}{|l|}{ Migration background (Native=ref.) } \\
\hline Foreigner from Europe & & & $\begin{array}{l}-0.571 * * * \\
(0.098)\end{array}$ \\
\hline Foreigner from outside Europe & & & $\begin{array}{l}-0.571 * * * \\
(0.129)\end{array}$ \\
\hline Unemployment rate & & & $\begin{array}{l}0.215 \\
(0.299)\end{array}$ \\
\hline Constant & $\begin{array}{l}-0.664 \sim \\
(0.376)\end{array}$ & $\begin{array}{l}-0.932 * * \\
(0.340)\end{array}$ & $\begin{array}{l}-1.632 * * * \\
(0.339)\end{array}$ \\
\hline Country variance & $\begin{array}{l}3.663 * * * \\
(1.082)\end{array}$ & $\begin{array}{l}2.748 * * * \\
(0.813)\end{array}$ & $\begin{array}{l}2.629 * * * \\
(0.779)\end{array}$ \\
\hline $\mathrm{N}$ country & 26 & 26 & 26 \\
\hline $\mathrm{N}$ individual & 13,510 & 13,510 & 13,510 \\
\hline
\end{tabular}

$\sim p<0.10, * p<0.05, * * p<0.01, * * * p<0.001$; Standard errors in parentheses; Iceland is excluded from analyses because of missing data on paid parental leave duration 
Table A13. Multilevel logistic regression: estimates of the relation between parental leave use and NEET risks later in life - without controlling for use of ECEC (logits)

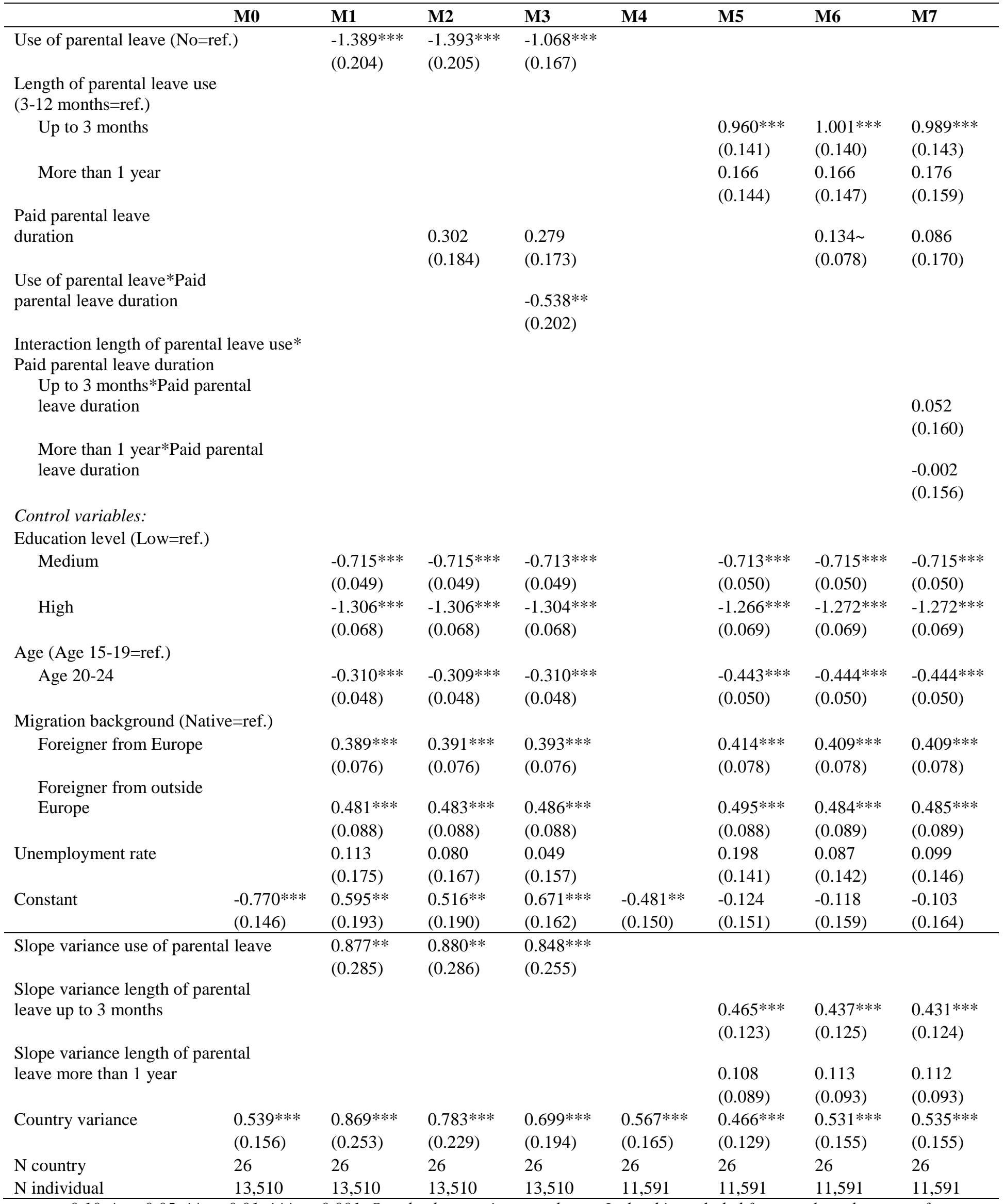
$\sim p<0.10, * p<0.05, * * p<0.01, * * * p<0.001$; Standard errors in parentheses; Iceland is excluded from analyses because of missing data on paid parental leave duration; the number of individuals is lower in Models 4-7 because we left out mothers who are still on parental leave 
Table A14. Multilevel logistic regression: estimates of the relation between family policies and use of ECEC-without controlling for use of parental leave (logits)

\begin{tabular}{|c|c|c|c|c|c|c|}
\hline & M0 & M1 & M2 & M3 & M4 & M5 \\
\hline Guaranteed childcare placement (No=ref.) & & $\begin{array}{l}0.844 * * \\
(0.260)\end{array}$ & $\begin{array}{l}0.805 * * \\
(0.250)\end{array}$ & & & \\
\hline \multicolumn{7}{|l|}{ Childcare costs } \\
\hline Control variables: & & & & & $\begin{array}{l}0.025 \\
(0.144)\end{array}$ & $\begin{array}{l}0.047 \\
(0.141)\end{array}$ \\
\hline \multicolumn{7}{|l|}{ Education level (Low=ref.) } \\
\hline Medium & & & $\begin{array}{l}0.166^{* * * *} \\
(0.049)\end{array}$ & & & $\begin{array}{l}0.151 * * \\
(0.049)\end{array}$ \\
\hline High & & & $\begin{array}{l}0.140 * \\
(0.061)\end{array}$ & & & $\begin{array}{l}0.129 * \\
(0.062)\end{array}$ \\
\hline \multicolumn{7}{|l|}{ Age (Age 15-19=ref.) } \\
\hline Age 20-24 & & & $\begin{array}{l}0.524 * * * \\
(0.049)\end{array}$ & & & $\begin{array}{l}0.532 * * * \\
(0.050)\end{array}$ \\
\hline \multicolumn{7}{|l|}{ Migration background (Native=ref.) } \\
\hline Foreigner from Europe & & & $\begin{array}{l}-0.041 \\
(0.074)\end{array}$ & & & $\begin{array}{l}-0.058 \\
(0.075)\end{array}$ \\
\hline Foreigner from outside Europe & & & $\begin{array}{l}-0.140 \\
(0.086)\end{array}$ & & & $\begin{array}{l}-0.167 \sim \\
(0.087)\end{array}$ \\
\hline Unemployment rate & & & $\begin{array}{l}-0.142 \\
(0.098)\end{array}$ & & & $\begin{array}{l}-0.184 \\
(0.122)\end{array}$ \\
\hline Constant & $\begin{array}{l}-0.587 * * * \\
(0.129)\end{array}$ & $\begin{array}{l}-0.782 * * * \\
(0.124)\end{array}$ & $\begin{array}{l}-1.292 * * * \\
(0.129)\end{array}$ & $\begin{array}{l}-0.558 * * * \\
(0.133)\end{array}$ & $\begin{array}{l}-0.558 * * * \\
(0.133)\end{array}$ & $\begin{array}{l}-1.067 * * * \\
(0.137)\end{array}$ \\
\hline Country variance & $\begin{array}{l}0.421 * * * \\
(0.121)\end{array}$ & $\begin{array}{l}0.296 * * * \\
(0.086)\end{array}$ & $\begin{array}{l}0.272 * * * \\
(0.079)\end{array}$ & $\begin{array}{l}0.447 * * * \\
(0.129)\end{array}$ & $\begin{array}{l}0.447 * * * \\
(0.128)\end{array}$ & $\begin{array}{l}0.409 * * * \\
(0.118)\end{array}$ \\
\hline $\mathrm{N}$ country & 26 & 26 & 26 & 26 & 26 & 26 \\
\hline $\mathrm{N}$ individual & 13,510 & 13,510 & 13,510 & 13,428 & 13,428 & 13,428 \\
\hline
\end{tabular}

$\sim p<0.10, * p<0.05, * * p<0.01, * * * p<0.001$; Standard errors in parentheses; Iceland is excluded from Models 0-2, and Cyprus is excluded from Models 3-5 because of missing data on the related family policy 
Table A15. Multilevel logistic regression: estimates of the relation between childcare use and NEET risks later in life - without controlling for use of parental leave (logits)

\begin{tabular}{l} 
Mo \\
\hline Use of ECEC (No=ref.) \\
$\begin{array}{l}\text { Guaranteed childcare placement } \\
\text { (No=ref.) }\end{array}$ \\
$\begin{array}{l}\text { Use of ECEC*Guaranteed childcare } \\
\text { placement }\end{array}$
\end{tabular}

placement

Childcare costs

Use of ECEC*Childcare costs

Control variables:

Education level

(Low=ref.)

Medium

Age (Age 15-19=ref.)

Age 20-24

Migration background

(Native=ref.)

Foreigner from

Europe

Foreigner from

outside Europe

Unemployment rate

Constant

$0.347 *$

$-0.790 * * *$
$(0.047)$

$-0.789 * * *$

(0.047)

$-1.298 * * *$

$-1.296 * * *$

$-0.789 * * *$

(0.047)

(0.066)

(0.066)

$-1.296 * * *$

$-0.312 * * *$

$-0.312 * * *$

(0.047)

(0.047)

$-0.312 * * *$

(0.047)

$0.066)$

$\begin{array}{lll}0.494 * * * & 0.493 * * * & 0.494 * * * \\ (0.074) & (0.074) & (0.074)\end{array}$

$0.543 * * * \quad 0.543 * * * \quad 0.543 * * *$

$\begin{array}{lll}(0.088) & (0.088) & (0.088)\end{array}$

$\begin{array}{lll}0.040 & 0.029 & 0.030\end{array}$

(0.119)

$0.460 * *$

(0.119)

$0.463 * *$
$-0.274 \sim$

(0.141)

$-0.276 \sim$

$(0.141)$

0.024

(0.121)

(0.152)

(0.152)

$-0.778 * * *$

(0.146)

Slope variance use of

ECEC

(0.146)

$$
0.539 * * *
$$

$0.225^{* *}$

$0.228 * *$

$0.220 * *$

(0.084)

(0.085)

(0.082)

$0.448 * * *$

$0.402 * * *$

$0.400 * * *$

(0.120)

(0.133)

(0.121)

26

26

13,510 26

13,510

26

13,510

$\mathrm{N}$ individual

13,510

$\sim p<0.10, * p<0.05, * * p<0.01, * * * p<0.001$; Standard errors in par from Models 4-7 because of missing data on the related family policy 
Table A16. Multilevel logistic regression: estimates of the relation between family policies and use of parental leave random 50\% young mothers per country (logits)

\begin{tabular}{|c|c|c|c|}
\hline & M0 & M1 & M2 \\
\hline Paid parental leave duration & & $\begin{array}{l}0.941 * * \\
(0.337)\end{array}$ & $\begin{array}{l}0.872 * * \\
(0.333)\end{array}$ \\
\hline \multicolumn{4}{|l|}{ Control variables: } \\
\hline Use of ECEC (No=ref.) & & & $\begin{array}{l}0.133 \sim \\
(0.072)\end{array}$ \\
\hline \multicolumn{4}{|l|}{ Education level (Low=ref.) } \\
\hline Medium & & & $\begin{array}{l}0.670 * * * \\
(0.084)\end{array}$ \\
\hline High & & & $\begin{array}{l}0.629 * * * \\
(0.106)\end{array}$ \\
\hline \multicolumn{4}{|l|}{ Age (Age 15-19=ref.) } \\
\hline Age $20-24$ & & & $\begin{array}{l}0.404 * * * \\
(0.079)\end{array}$ \\
\hline \multicolumn{4}{|l|}{ Migration background (Native=ref.) } \\
\hline Foreigner from Europe & & & $\begin{array}{l}-0.826 * * * \\
(0.141)\end{array}$ \\
\hline Foreigner from outside Europe & & & $\begin{array}{l}-0.670 * * * \\
(0.192)\end{array}$ \\
\hline Unemployment rate & & & $\begin{array}{l}0.249 \\
(0.298)\end{array}$ \\
\hline Constant & $\begin{array}{l}-0.640 \sim \\
(0.370) \\
\end{array}$ & $\begin{array}{l}-0.896 * * \\
(0.339) \\
\end{array}$ & $\begin{array}{l}-1.628 * * * \\
(0.344)\end{array}$ \\
\hline Country variance & $\begin{array}{l}3.521 * * * \\
(1.048)\end{array}$ & $\begin{array}{l}2.693 * * * \\
(0.804)\end{array}$ & $\begin{array}{l}2.587 * * * \\
(0.774)\end{array}$ \\
\hline $\mathrm{N}$ country & 26 & 26 & 26 \\
\hline $\mathrm{N}$ individual & 6,736 & 6,736 & 6,736 \\
\hline
\end{tabular}

$\sim p<0.10, * p<0.05, * * p<0.01, * * * p<0.001$; Standard errors in parentheses; Iceland is excluded from analyses because of missing data on paid parental leave duration 
Table A17. Multilevel logistic regression: estimates of the relation between parental leave use and NEET risks later in life - random 50\% young mothers per country (logits)

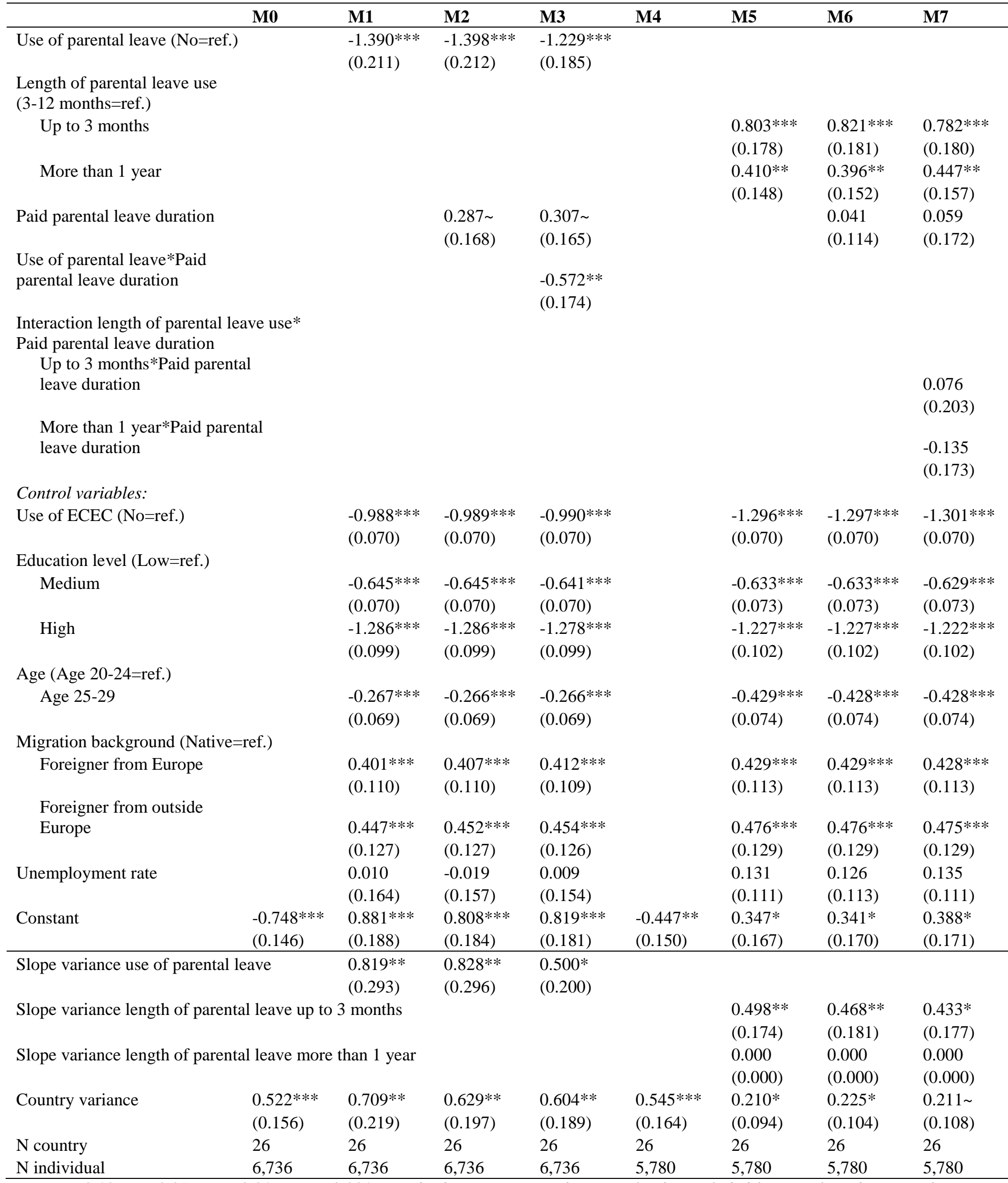
$\sim p<0.10, * p<0.05, * * p<0.01, * * * p<0.001$; Standard errors in parentheses; Iceland is excluded from analyses because of missing data on paid parental leave duration; the number of individuals is lower in Models 4-7 because we left out mothers who are still on parental leave 
Table A18. Multilevel logistic regression: estimates of the relation between family policies and use of ECEC-random $50 \%$ young mothers per country (logits)

\begin{tabular}{|c|c|c|}
\hline M0 & M1 & M2 \\
\hline Guaranteed childcare placement $(\mathrm{No}=\mathrm{ref})$. & $\begin{array}{l}0.947 * * * \\
(0.287)\end{array}$ & $\begin{array}{l}0.885 * * \\
(0.282)\end{array}$ \\
\hline
\end{tabular}

M3 $\quad$ M4

Childcare costs

$\begin{array}{ll}0.010 & 0.027 \\ (0.158) & (0.156)\end{array}$

Control variables:

Use of parental leave (No=ref.)

$0.122 \sim$

$0.132 \sim$

(0.071)

Education level (Low=ref.)

\section{Medium}

High

Age (Age 20-24=ref.)

Age 25-29

Migration background (Native=ref.)

Foreigner from Europe

Foreigner from outside Europe

\section{Constant}

Country variance

$\mathrm{N}$ country

$\mathrm{N}$ individual

$$
\begin{aligned}
& 0.193 * * \\
& (0.069) \\
& 0.114 \\
& (0.088)
\end{aligned}
$$

(0.121)

$-0.160$

$-0.202$

(0.111)

(0.136)

$-1.365 * * * \quad-0.533 * * * \quad-0.533 * * *$

$-1.116^{* * *}$

(0.143)

(0.137)

(0.153)

$(0.147)$

(0.147)

(0.160)

$\begin{array}{llll}(0.153) & (0.147) & (0.147) & (0.160) \\ 0.332 * * & 0.529 * * * & 0.529 * * * & 0.490 * * *\end{array}$

$\begin{array}{llllll}(0.150) & (0.105) & (0.101) & (0.157) & (0.157) & (0.147)\end{array}$

$(0.150)$

26

26

26

26

26

$\sim p<0.10, * p<0.05, * * p<0.01, * * * p<0.001 ;$ Standard errors in parentheses; Iceland is excluded from Models 0-2, and Cyprus is excluded from Models 3-5 because of missing data on the related family policy 
Table A19. Multilevel logistic regression: estimates of the relation between childcare use and NEET risks later in life - random $50 \%$ young mothers per country (logits)

\begin{tabular}{l} 
Mo \\
\hline Use of ECEC (No=ref.) \\
$\begin{array}{l}\text { Guaranteed childcare placement } \\
\text { (No=ref.) }\end{array}$ \\
$\begin{array}{l}\text { Use of ECEC*Guaranteed childcare } \\
\text { placement }\end{array}$
\end{tabular}

Childcare costs

Use of

ECEC*Childcare costs

$\begin{array}{lll}\text { M1 } & \text { M2 } & \text { M3 } \\ -0.945^{* * * *} & -0.940 * * * & -0.986 * * * \\ (0.148) & (0.148) & (0.166) \\ & -0.313 & -0.344 \\ & (0.340) & (0.345)\end{array}$

$(0.363)$ M4 M5

$-0.953 * * * \quad-0.952 * * * \quad-0.955 * * *$

$(0.150) \quad(0.150) \quad(0.149)$

(0.340)

Control variables:

Use of parental leave

(No=ref.)

Education level

(Low=ref.)

Medium

High

Age (Age 20-24=ref.)

Age 25-29

Migration background

(Native=ref.)

Foreigner from

Europe

Foreigner from

outside Europe

Unemployment rate

Constant$$
0.748 * * * 20.835 * *+20
$$

$0.414 * * *$

$0.414 * * *$

$0.415^{* * *}$

(0.108)

(0.108)

(0.108)

$0.437 * * *$

$0.436 * * *$

$0.436 * * *$

(0.127)

(0.127)

(0.127)

0.094

0.087

0.088

(0.131)

(0.131)

$0.835 * * *$

$0.901 * * *$

$0.904 * * *$

(0.172)

(0.173)

$-0.770 * * *$

$-1.538 * * *$

(0.079)

$-0.134$

$-0.129$

(0.157)

(0.157)

$-0.064$

(0.163)

Slope variance use of

ECEC

(0.146)

(0.159)

(0.148)

$\begin{array}{lll}-0.633 * * * & -0.631 * * * & -0.631 * * * \\ (0.070) & (0.070) & (0.070) \\ -1.266 * * * & -1.264 * * * & -1.264 * * * \\ (0.099) & (0.099) & (0.099) \\ & & \\ -0.246 * * * & -0.246 * * * & -0.246 * * * \\ (0.068) & (0.068) & (0.068)\end{array}$

Country variance

$0.392 * \quad 0.398 * \quad 0.393 *$

(0.158)

(0.160)

(0.157)

$0.453 * *$

$0.455 * *$

(0.145)

(0.145)

$\mathrm{N}$ country

(0.156)

$\mathrm{N}$ individual 26

(0.150)

26

26

6,725

6,725

0

\section{$0.415 * * *$}

(0.110)

$0.414 * * *$

$0.414 * * *$

$0.386 * *$

(0.110)

(0.110)

$\sim p<0.10, * p<0.05, * * p<0.01, * * * p<0.001 ;$ Standard errors in parentheses; Iceland is excluded from Models 0-3 and Cyprus from Models 4-7 because of missing data on the related family policy 
Table A20. Multilevel logistic regression: estimates of the relation between parental leave use and NEET risks later in life - macro-data from 2004 (logits)

\begin{tabular}{llll}
\hline & M0 & M1 & M2 \\
\hline Paid parental leave duration & & $0.876^{*}$ & $0.873^{*}$ \\
Control variables: & & $(0.372)$ & $(0.359)$
\end{tabular}

Use of ECEC (No=ref.)

$0.151 * *$

(0.050)

Education level (Low=ref.)

$0.663 * * *$

(0.059)

$0.573 * * *$

High

(0.074)

Age (Age 15-19=ref.)

Age 20-24

$0.393 * * *$

(0.055)

Migration background (Native=ref.)

Foreigner from Europe

$-0.570 * * *$

(0.098)

Foreigner from outside Europe

$-0.567 * * *$

(0.129)

0.342

(0.305)

Unemployment rate

$-1.603 * * *$

Constant

-0.664

$-0.848 *$

(0.344)

Country variance

(0.376)

(0.351)

$2.791 * * *$

(1.082)

$\mathrm{N}$ country

26

$3.013 * * *$

(0.827)

$\mathrm{N}$ individual

13,510

(0.892)

26

$\sim p<0.10, * p<0.05, * * p<0.01, * * * p<0.001 ;$ Standard errors in parentheses; Iceland is excluded from analyses because of missing data on paid parental leave duration 
Table A21. Multilevel logistic regression: estimates of the relation between parental leave use and NEET risks later in life - macro-data from 2004 (logits)

\begin{tabular}{|c|c|c|c|c|c|c|c|}
\hline M0 & M1 & M2 & M3 & M4 & M5 & M6 & M7 \\
\hline Use of parental leave ( $\mathrm{No}=$ ref. $)$ & $\begin{array}{l}-1.411 * * * \\
(0.203)\end{array}$ & $\begin{array}{l}-1.415^{* * * *} \\
(0.204)\end{array}$ & $\begin{array}{l}-1.277^{* * * *} \\
(0.170)\end{array}$ & & & & \\
\hline \multicolumn{8}{|c|}{ Length of parental leave use (3-12 months=ref.) } \\
\hline Up to 3 months & & & & & $\begin{array}{l}0.809 * * * \\
(0.145)\end{array}$ & $\begin{array}{l}0.882 * * * \\
(0.143)\end{array}$ & $\begin{array}{l}0.835^{* * * *} \\
(0.140)\end{array}$ \\
\hline More than 1 year & & & & & $\begin{array}{l}0.266^{*} \\
(0.125)\end{array}$ & $\begin{array}{l}0.241 \sim \\
(0.130)\end{array}$ & $\begin{array}{l}0.294 * \\
(0.126)\end{array}$ \\
\hline $\begin{array}{l}\text { Paid parental leave } \\
\text { duration }\end{array}$ & & $\begin{array}{l}0.419^{*} \\
(0.169)\end{array}$ & $\begin{array}{l}0.431^{*} \\
(0.168)\end{array}$ & & & $\begin{array}{l}0.185^{*} \\
(0.094)\end{array}$ & $\begin{array}{l}0.144 \\
(0.152)\end{array}$ \\
\hline
\end{tabular}

Use of parental

leave*Paid parental

leave duration

$-0.614 * * *$

$(0.170)$

Interaction length of parental leave use*Paid parental leave duration

Up to 3 months*Paid parental leave duration

0.092

$(0.159)$

More than 1 year*Paid parental leave duration

Control variables:

Use of ECEC

(No=ref.)

$$
\begin{array}{lll}
-0.969 * * * & -0.969 * * * & -0.969 * * * \\
(0.049) & (0.049) & (0.049)
\end{array}
$$

$$
\begin{array}{lll}
-1.274 * * * & -1.273 * * * & -1.276 * * * \\
(0.050) & (0.050) & (0.050)
\end{array}
$$

Education level

$$
\text { (Low=ref.) }
$$

Medium

High

Age (Age 20-24=ref.)

Age 25-29

Migration background (Native=ref.)

Foreigner from

Europe

$\begin{array}{lll}-0.709 * * * & -0.708 * * * & -0.707 * * * \\ (0.050) & (0.050) & (0.050) \\ -1.310 * * * & -1.310 * * * & -1.307 * * * \\ (0.069) & (0.069) & (0.069)\end{array}$

Foreigner from outside Europe

Unemployment rate

$\begin{array}{lll}-0.238 * * * & -0.236 * * * & -0.236 * * * \\ (0.049) & (0.049) & (0.049)\end{array}$

$0.399 * * * \quad 0.403 * * * \quad 0.405 * * *$

$\begin{array}{lll}(0.078) & (0.077) \quad(0.077)\end{array}$

$0.474 * * * \quad 0.477 * * * \quad 0.478 * * *$

$\begin{array}{lll}(0.090) & (0.090) \quad(0.090)\end{array}$

$\begin{array}{lll}0.083 & 0.091 & 0.098\end{array}$

$\begin{array}{lll}(0.163) & (0.147) \quad(0.146)\end{array}$

Constant

$-0.770 * * *$

$0.876 * * *$

$0.792 * * *$

$0.796 * * *$

(0.168)

Slope variance use of parental

$(0.146) \quad(0.182) \quad(0.168)$

leave

$\begin{array}{ll}0.859 * * & 0.865 * * \\ (0.283) & (0.284)\end{array}$

$0.510 * *$

(0.181)

Slope variance length of parental leave up to 3 months

Slope variance length of parental leave more than 1 year

\begin{tabular}{llllllllll} 
& & & & & & $(0.056)$ & $(0.063)$ & $(0.053)$ \\
Country variance & $0.539 * * *$ & $0.752 * * *$ & $0.601 * * *$ & $0.596 * * *$ & $0.567 * * *$ & $0.301 * *$ & $0.347 * *$ & $0.332 * * *$ \\
& $(0.156)$ & $(0.221)$ & $(0.178)$ & $(0.177)$ & $(0.165)$ & $(0.103)$ & $(0.107)$ & $(0.100)$ \\
N country & 26 & 26 & 26 & 26 & 26 & 26 & 26 & 26 \\
N individual & & & & & & & & 11,591 & 11,591 \\
\hline
\end{tabular}


$\sim p<0.10, * p<0.05, * * p<0.01, * * * p<0.001$; Standard errors in parentheses; Iceland is excluded from analyses because of missing data on paid parental leave duration; the number of individuals is lower in Models 4-7 because we left out mothers who are still on parental leave

Table A22. Multilevel logistic regression: estimates of the relation between family policies and use of ECEC-macrodata from 2004 (logits)

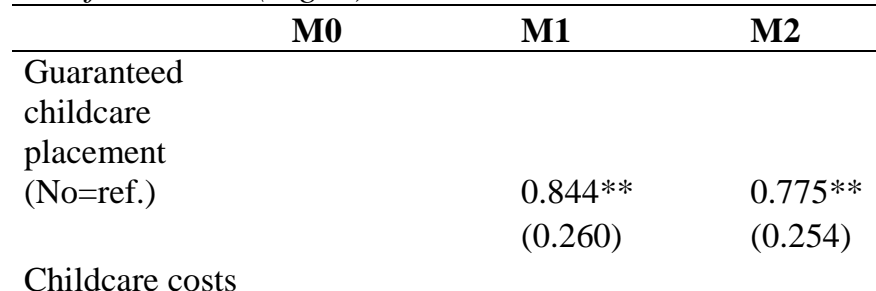

Control variables:

Use of parental

leave $(\mathrm{No}=$ ref.)
$0.149 * *$
$0.134 *$
(0.050)
(0.054)

Education level

(Low=ref.)

\section{Medium}

High

Age (Age 20-

24=ref.)

Age 25-29

Migration

background

(Native=ref.)

Foreigner

from Europe

Foreigner

from outside

Europe

Unemployment

rate

\section{Constant}

$$
(0.129)
$$

$0.421 * * *$

(0.121)

$\mathrm{N}$ country 26

13,510

$0.153 * *$

$0.093 \sim$

(0.049)

$0.130 *$

(0.062)

$0.515 * * *$

$-0.090$

$-0.033$

(0.164)

$(0.161)$

(0.050)

$0.478 * * *$

(0.053)

0.087

(0.066)

$-0.030$

$-0.073$

(0.074)

(0.078)

$-0.130$

$-0.164 \sim$

(0.086)

(0.087)

$-0.151$

$-0.302 \sim$

(0.099)

(0.166)

$\begin{array}{llll}-1.334 * * * & -0.496 * * & -0.501 * * * & -1.047 * * *\end{array}$

Country variance

$\mathrm{N}$ individual

$-0.782 * * *$

(0.132)

$(0.153)$

(0.152)

(0.157)

$0.296 * * *$

$0.281 * * *$

$0.454 * *$

$0.446 * *$

$0.387 * *$

(0.082)

(0.148)

(0.146)

$(0.128)$

26

26

20

20

20

$13,510 \quad 11,495 \quad 11,495$

11,495

$\sim p<0.10, * p<0.05, * * p<0.01, * * * p<0.001 ;$ Standard errors in parentheses; Iceland is excluded from Models 0-2, and Cyprus is excluded from Models 3-5 because of missing data on the related family policy 
Table A23. Multilevel logistic regression: estimates of the relation between childcare use and NEET risks later in life - macro-data from 2004 (logits)

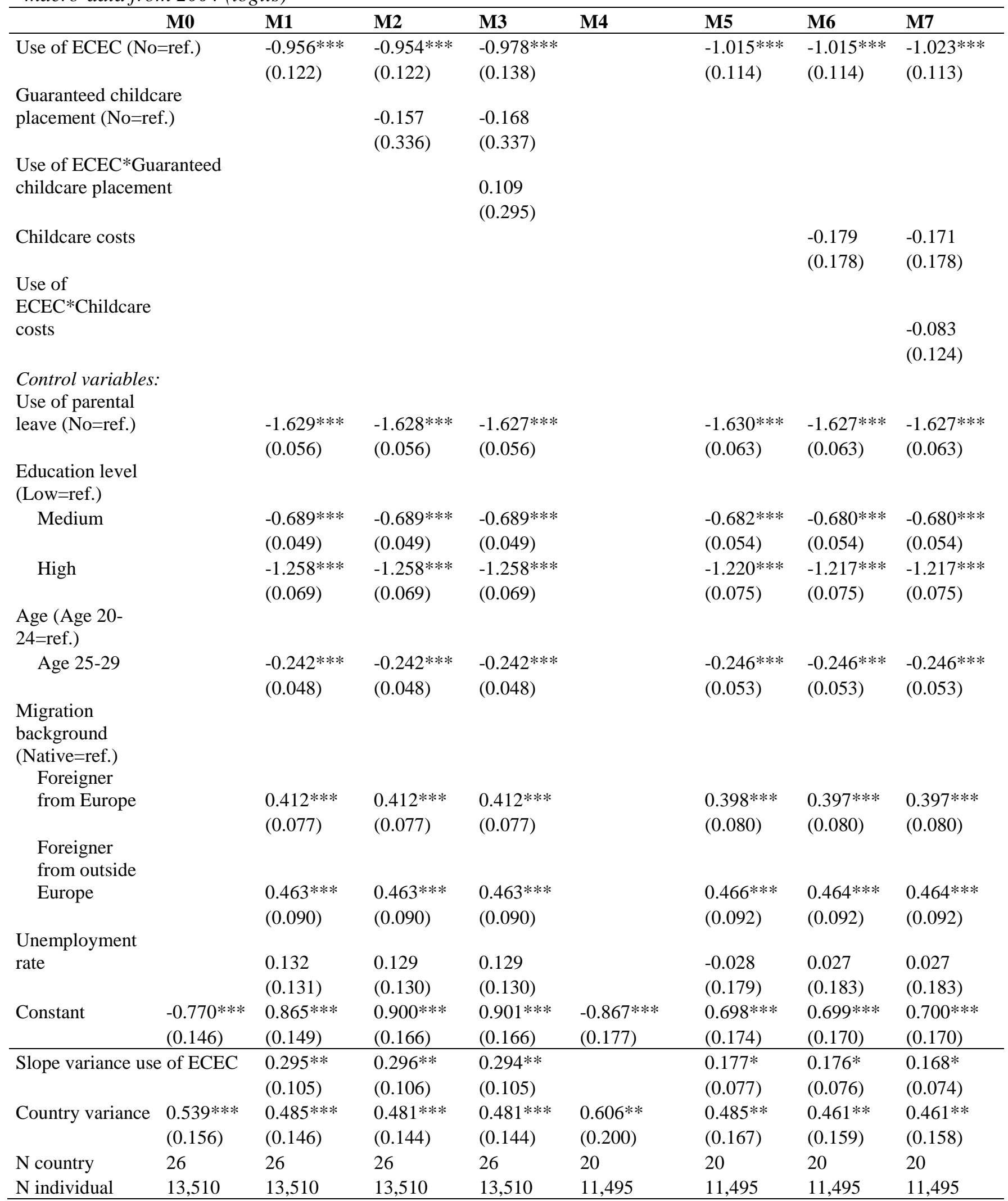

$\sim p<0.10, * p<0.05, * * p<0.01, * * * p<0.001$; Standard errors in parentheses; Iceland is excluded from Models 0-3 and Cyprus from Models 4-7 because of missing data on the related family policy 